Citation: K.A. Nguyen, R.A. Stewart, H. Zhang, An intelligent pattern recognition model to automate the categorisation of residential water end-use events, Environmental Modelling \& Software, Volume 47, September 2013, Pages 108-127, ISSN 1364-8152, http://dx.doi.org/10.1016/j.envsoft.2013.05.002.

\title{
AN INTELLIGENT PATTERN RECOGNITION MODEL TO AUTOMATE THE CATEGORISATION OF RESIDENTIAL WATER END-USE EVENTS
}

K.A. Nguyen, R.A. Stewart and H. Zhang*

Griffith School of Engineering, Centre for Infrastructure Engineering and Management

Griffith University, Gold Coast Campus, QLD 4222, Australia.

Submitted to Environmental Modelling \& Software, 07 August, 2012

Revised on May 01, 2013

*Author to whom all correspondence should be addressed. Tel.: +61 75552 9015; Fax: +61 75552 8065. Email: hong.zhang@griffith.edu.au 


\begin{abstract}
The rapid dissemination of residential water end-use (e.g. shower, clothes washer, etc.) consumption data to the customer via a web-enabled portal interface is becoming feasible through the advent of high resolution smart metering technologies. However, in order to achieve this paradigm shift in residential customer water use feedback, an automated approach for disaggregating complex water flow trace signatures into a registry of end-use event categories needs to be developed. This outcome is achieved by applying a hybrid combination of gradient vector filtering, Hidden Markov Model (HMM) and Dynamic Time Warping Algorithm (DTW) techniques on an existing residential water end-use database of 252 households located in South-east Queensland, Australia having high resolution water meters (0.0139 L/pulse), remote data transfer loggers (5s logging) and completed household water appliance audits. The approach enables both single independent events (e.g. shower event) and combined events (i.e. several overlapping single events) to be disaggregated from flow data into a comprehensive end-use event registry. Complex blind source separation of concurrently occurring water end use events (e.g. shower and toilet flush occurring in same time period) is the primary focus of this present study. Validation of the developed model is achieved through an examination of 50 independent combined events.
\end{abstract}

Key words: water end-use event, water micro-component, residential water flow trace disaggregation, hidden markov model, dynamic time warping algorithm, gradient vector filtering, water demand management 


\section{Introduction}

\subsection{Advanced Role of Sensor technology and 'big data' analytics in water resources management}

Sensor technology and the 'big data' they generate combined with advanced machine learning techniques provide numerous opportunities for enhancing outdated approaches covering all the various segments of water resources management (Schimack et al. 2010; Uslander et al. 2010). Reported studies demonstrate that such technologies and techniques are increasingly influencing how we better monitor and manage large-scale water basins (e.g. White et al. 2006; Quinn et al. 2010; Murla et al. 2010), river stream flow (Limdim et al. 2010; David et al. 2013), drinking water reservoir quality (Glasgow et al. 2004), water treatment plant operations (Storey et al. 2011), water distribution system networks (Dorini et al. 2006), consumer water end use consumption (Nguyen et al. 2013a; Willis et al. 2011c), and wastewater plant operations (Durrenmatt and Gujer, 2012). The research focus of this paper is on the application of sensors (i.e. high resolution smart meters) and 'big data' analytical techniques at the urban water scale; specifically the residential water consumer and their end use water consumption. This frontier area of water end use or micro-component analysis research is beginning to attract research attention. Froehlich et al. (2011) conducted a study using pressure sensing devices to infer water usage events in households in Washington State, USA. CSIRO (2012) have recently combined an acoustic sensor with smart water metering systems in order to disaggregate residential water consumption into end use categories. The authors (Nguyen et al. 2013a) utilised machine learning techniques such as HMM and DTW to disaggregate remotely collected high resolution water flow data received from smart meters into single end use event categories, which is the precursor to this present paper seeking to disaggregate concurrently occurring end use events. With these technologies becoming commercially viable, the vision of an intelligent expert system, which can perform autonomous water end use analysis and provide feedback and decision support to both water consumers and authorities, is rapidly becoming a reality.

\subsection{Vision of an advanced urban water management system}

The era when urban water planning focused only on how to build and supply water has been replaced by a new paradigm, where the precise accounting and management of urban water consumption is deemed essential to maintenance of a sustainable water future. Lower water yield reliability, from traditional water supply sources, and the increasing demand for water 
in urban areas, requires the development of a more adaptive and innovative water resource management approach, fed by robust real-time information. As a consequence, an increasing number of smart water metering technologies have been introduced to the market. Such metering devices embrace two distinct elements: meters that use new technology to capture water use information; and communication systems that can capture and transmit real-time water use information (Stewart et al. 2010). While current forms of smart metering technology can provide total consumption data to the customer and utility at high levels of resolution, they fail to disaggregate this data into its end-use use categories. This study envisions and provides the architecture for an advanced smart metering system that enables customers and utilities to actively monitor, through web-portal interfaces, real-time information about what, when, where and how water was consumed at their meter connection (e.g. 56 litre shower occurring between 06:55-07:15 Tuesday 25 May 2012). The proposed system allows individual consumers to log into their user-defined water consumption web page to view their daily, weekly, and monthly consumption tables, as well as charts on their water end-use patterns across major end use categories (e.g. leaks, clothes washer, dishwasher, tap, toilet, shower and irrigation). It can also rapidly alert them of occurring leak events so that they can immediately address them instead of the current slow feedback process from current metering technology (e.g. monthly or quarterly alert at best).

The analytical report generated by the new advanced integrated water management system will help utilities identify the water consumption patterns of their various consumer types and assist with a range of urban water planning and management functions (Stewart et al. 2010). However, such a system requires a robust analytical model to automatically and accurately disaggregate the flow trace data into individual water end-use event categories. Current enduse disaggregation processes used by the authors and their aligned research teams requires extensive manual data collection and analysis as summarised in Figure 1 (Beal et al. 2011a). Automation of this resource intensive process is essential to developing the proposed advanced water management system that has commercial viability. The design and verification of an automated flow pattern recognition model that has good accuracy is the ultimate aim of this study. 


\subsection{Review of reported water end use studies and analysis approaches applied}

In recent years, a number of residential water end use studies have been completed using a range of single or mixed methods, such as household auditing, diaries, high resolution smart metering and pressure sensors, with a diverse range of per capita end use summaries. Jacobs (2007) and Blokker (2010) provided summaries on a good proportion of the end use models developed from stochastic techniques, contingent valuation approaches (CVA), modelling, and metered methods. The introduction of advanced technology has enabled the direct capture and classification of water end use events. Table 1 provides a summary of reported end use studies that have applied high resolution smart meters, data loggers or pressure sensors completed internationally in the last 15 years.

\section{[Insert Table 1]}

As displayed in Table 1, from a direct measurement and water end use recognition approach which is undoubtedly the future of this type of problem, the two main approaches presently reported include using smart water meters in conjunction with a decision-tree based analysis tool such as Trace Wizard or Identiflow or as more recently published, the inclusion of pressure sensors at individual appliances (i.e. HydroSense) along with a HMM based decision tool. Each approach has its own strengths and weaknesses, which were discussed in detail in (Nguyen et al., 2013a).

In summary, the ideal approach that is most amenable to citywide application is installing smart water meters at the property boundary in conjunction with intelligent end use pattern recognition algorithms either in-built into the meter software or within a processing module at the utilities data centre. This is the lowest cost and non-intrusive approach to water end use disaggregation. However, for such widespread implementation, the following summarised limitations of the existing models (i.e. Trace Wizard and Identiflow) have to be overcome:

- inability to analyse collected data without human interaction and manual reclassification (i.e. main disadvantage);

- inability to accurately distinguish different end use categories which have similar water flow characteristics (e.g. shower, bathtub and irrigation);

- inability to classify an end use category that has various physical parameters depending on appliance models (e.g. dishwasher, clothes washer and toilet); and 
- inability to deal with multi-layer combined events (i.e. cannot handle three or more concurrent events).

These shortcomings have motivated the development of an automatic flow trace analysis system which can address all of the above mentioned issues. For the building of such an intelligent model, an in-depth understanding of the existing techniques applied to this type of problem is required. Nguyen et al. (2013a) presented a detailed review of pattern recognition techniques available and provided a rating for them (i.e. 1 star $(*)=$ poor; $* *=$ below average; $* * *=$ average; $* * * *=$ good; and $* * * * *=$ excellent $)$ for their processing time efficiency, classification accuracy, self-learning potential and an overall applicability rating for each technique to the herein examined water end use pattern recognition process (Table 2).

\section{[Insert Table 2]}

Based on this review Nguyen et al. (2013a) suggested a method using a hybrid combination of the Hidden Markov Model (HMM) and Dynamic Time Warping (DTW) algorithm to help classify single independent events into appropriate end use categories. However, in residential households a small proportion of water end use events are occurring simultaneously (e.g. shower and toilet flush). Therefore, in order to achieve the vision of an automated and intelligent water management system, this current paper presents a robust method which integrates the analytical techniques employed in single event classification with vector gradient filtering method to perform a comprehensive combined event analysis. A detailed literature review of HMM and DTW techniques, including their theoretical foundations and application to single event analysis has been conducted in Nguyen et al. (2013a). This present paper only summarises the applied HMM and gradient vector filtering methods and outlines their crucial roles in combined event disaggregation.

\subsection{Overview of applied pattern recognition techniques}

HMM is a statistical Markov model in which the system being modelled is assumed to be a Markov process with unobserved (hidden) states. In a regular Markov model the visible state transition probabilities are the only parameters. In a hidden Markov model, the state is not directly visible, but the output, which is dependent on the state, is visible. Each state has a probability distribution over the possible output tokens. Therefore, the sequence of tokens generated by an HMM gives some information about the sequence of the states (Ephraim and 
Merhav, 2002). HMM was used as the principal technique for the classification of all single end use events in (Nguyen et al., 2013a). In the present study, the existing HMM model, which was previously applied in single event analysis, is incorporated with some additional physical parameters to help disaggregate a combined event into many samples and assign them to specific end-use categories.

Another mathematical tool is utilised for combined event analysis, namely, gradient vector filtering. This technique has been widely applied in many fields such as image enhancement, noise reduction or digital signal enhancement (Boashash, 2003). It relies on the analysis of the multi-dimensional gradient vector of the original signal to extract information contained in the signal, so that unnecessary parts can be filtered or removed (Shapiro and George, 1998). Based on that principle, another version of this technique has been developed to suit this particular study. The proposed method also considers the gradient change of the flow rate data series to determine whether a flow rate fluctuation is actually a new event occurring on top of the base event or expected variation within the base event.

\section{Research objective}

The development of pattern matching algorithms which are able to automatically categorise the collected flow trace data points, received from the wireless data loggers, into particular water end-use categories requires the resolution of two key research questions; firstly, how to recognise single events from the collected flow trace?; and, secondly, how to separate a combined event into its appropriate single event categories? The first research question was successfully achieved using a hybrid combination of the HMM and DTW algorithm (Nguyen et al., 2013a). The key objective of this current investigation is to solve the latter more challenging problem of disaggregating multiple combinations of simultaneously occurring water end use events in residential households into single events assigned to their appropriate end use category. Validation of the developed combined event disaggregation model is achieved through its application and accuracy testing on 50 independently collected combined events.

\section{Model input data}

\subsection{Research regions}

Data utilised for the development of the model is sourced from 252 residential households fitted with a smart meter and data logger and located in the urban south east corner of the 
State of Queensland, Australia. These households are consenting participants in the recently completed South-east Queensland Residential End Use Study (SEQREUS) funded by the Queensland State Government (Beal and Stewart, 2012). A sample of properties is taken from the Sunshine Coast Regional Council (n=67), Brisbane City Council (n=61), Ipswich City Council ( $n=37)$ and Gold Coast City Council $(n=87)$ to use as a database for the study.

\subsection{Winter and summer samples}

Three separate water end use analysis reads occurred during the study. The first read was conducted in winter 2010 from $14^{\text {th }}$ to the $28^{\text {th }}$ June. The second read was taken in the summer 2010-11 between $1^{\text {st }}$ December 2010 and $21^{\text {st }}$ February 2011. The final two week period of analysis occurred in winter 2011 from the $1^{\text {st }}$ to the $15^{\text {th }}$ June. It is important to obtain a dataset for this study that included the entire spectrum of events across seasonal periods (i.e. irrigation). While seasonal affects may induce higher amounts of irrigation events from some householders on hot dry days and potentially different frequencies for event categories (i.e. longer showers in winter), the signature trace for particular end use event categories (e.g. clothes washer or shower pattern) are not particularly affected by seasonal influences (Beal et al. 2011b).

\subsection{Property selection}

To ensure the research findings are representative of a population, an appropriate sample must be selected (Howell, 2004). The study seeks to target just mains-only supplied detached dwellings which make up the majority of residential stock in the region at present. Participating households were requested to complete a questionnaire survey developed to assist in determining the socio-demographic characteristics and socioeconomic status of households. These surveys also assisted in determining environmental and water conservation perceptions and attitudes of consumers. The completed questionnaire surveys $(n=252)$ were entered into Predictive Analytics Software 18.0 (PASW formally SPSS), a statistical analysis program. PASW 18.0 is a popular data storage platform and statistical analysis software with researchers and businesses. Descriptive statistical enquiries were carried out to determine the socio-demographic characteristic of the research sample. The outcome of this analysis process was the decision on certain criteria for sample selection as displayed in Table 3 below.

\section{[Insert Table 3]}




\subsection{Characteristics of participating households}

Some general characteristics of the participating households within each region are shown in Table 4. The average number of people per household is relatively consistent across all regions for all three measurement periods, with the Sunshine Coast having the lowest average occupancy of 2.5 people per household, and the Gold Coast region having the highest average of 2.9 occupants. The percentage of households occupied by two or less people is greater in the Sunshine Coast (average of $56 \%$ ) and Gold Coast (49\%) compared to the generally larger households in Ipswich (53 \%) and Brisbane (43\%). These percentages reflect the older demographic of the Sunshine Coast and Gold Coast regions which is also typified by the older age of children for these regions (Table 4).

\section{[Insert Table 4]}

\subsection{Collected unprocessed flow dataset utilised for study}

As mentioned in the provided abstract, CSV files containing $0.0139 \mathrm{~L} /$ pulse water consumption data for every five second logging interval for each sample household was collected. To enable the application of HMM, water flow data collected was initially processed and broken down into eight different water end use categories with the number of samples shown in the second column of Table 5. The database was then apportioned into a training (80\%) and testing (20\%) data set.

\section{[Insert Table 5]}

\section{Model architecture}

\subsection{End use classification process overview}

With the available database, the disaggregation process of the water end-use events from the raw data is developed and shown in Figure 2. As mentioned previously, single events are those which occur in isolation (e.g. toilet flushing only), while combined events have simultaneous occurrences of water usage (e.g. a shower occurring while someone else is using a tap), which is more challenging to disaggregate. At the very first step, HMM algorithm is used to recognise if an event is a single event or a combined event. The outcomes from this process are a group of classified single events and another group containing unclassified combined events. 
In the case of the single events, it is very likely that not all of them are correctly assigned to the appropriate categories due to the high complexity level of the present problem. Therefore, to achieve a reliable single event classification, additional techniques and criteria need to be utilised, in conjunction with the HMM technique. The detailed procedure is shown in Figure 3. The next important task involves the combined event classification, which remains one of the most complicated problems in the field of pattern matching. The detailed procedure is summarised in Figure 4.

\section{[Insert Figure 2]}

\subsection{Single event analysis}

The present study focuses on the combined event classification of the flow trace analysis system. However, a brief introduction and explanation of the required procedures for the achievement of a single event classification is presented in this section; a more detailed technical overview was provided by Nguyen et al. (2013a). The flow chart in Figure 3 illustrates a comprehensive single end-use event analysis process.

The analysis starts with identifying the leak event, which usually occurs in a continuous manner. The low-flow rate leak event pulses, recorded by the smart water meter (i.e. isolated 0.0139L events), are evident in a large proportion of the households. These events are initially extracted from the flow trace data set and are classified in the 'leak' end-use category. The remaining flow data is then analysed using the HMM to classify all the water end-use categories, usually into two broader groups: (1) depends heavily on a water user's behavior (related to tap, bathtub, irrigation, shower and toilet); and (2) works under a pre-set mechanical process (related to clothes washer and dishwasher). The HMM method categorises the water flow data into eight basic end-use categories (i.e. shower, clothes washer, dishwasher, tap, full flush toilet, half flush toilet, irrigation and bathtub) and a group of unclassified combined events (dashed line in Figure 2). The categorisation process of combined events is presented in the next section. In the single event classification, to strip out misclassified samples, which are also products obtaining from the initial HMM application where they exist, a screening process is further performed on all these classified single events to determine the one which do not fit neatly within a range of certain criteria for each particular end-use category. As a result, a number of classified single events are removed from their respective categories and relocated to a group titled inconclusive events. 
For the inconclusive event category, the DTW algorithm is applied to determine the clothes washer and dishwasher events, as these end-uses often have similar repeating mechanical wash cycles (i.e. related to others occurring within a short 1-2 hour time period). The event time-of-day probability functions (i.e. the probability of a certain event occurring at a certain time of day), combined with the HMM method, is then applied to classify the inconclusive end-use events which usually depend on user's behaviours (i.e. shower, tap, irrigation, toilet and bathtub). The process outlined in Figure 3, results in the classification of the raw flow trace data into a repository of water end-use events. The next primary step in the overall study is to perform a combined event classification.

\section{[Insert Figure 3]}

\subsection{Combined event analysis}

In the current study, a combined event is formed by at least two simultaneous single events. There is no restriction on the starting and finishing time of each component event, as long as they have an overlapped period with each other. This overlap makes the problem extremely complicated; no information is given on how many single events contribute to the combined event, or when each of them starts or finishes. Therefore, it is essential to explore the formation of a combined event to establish the criteria for the separation process.

An intensive analysis of the collected data reveals that most combined events last more than one minute, allowing enough time for many end-use categories to overlap. In a combined event, the longest component is named the "base-event", and all other shorter events are called "sub-events", which are superimposed on top of the base event (i.e. in Figure 8, Event 1 is defined as a base event, and all other events are named sub-events). An important finding is that most of the collected base events include the shower, bathtub and long irrigation, as they all last substantially longer than the other, shorter end-uses. Nevertheless, a toilet event associated with leaks can sometimes act as a base event due to the long lasting period of the leak; however, such case is insignificant as it would be stripped out from the raw data at the beginning of the analysis process. For sub-events, the most common categories are the tap, clothes washer, dishwasher, toilet, and short irrigation.

With the availability of the established HMM model for single event recognition, the analysis of a combined event is ready by using the same technique, in conjunction with other pre- 
determined criteria. The whole combined event analysis process is separated into two stages, the Sub-event analysis and the Base-event analysis, which are clearly presented in Figure 4.

In the first stage analysis, a separation process employing the modified gradient vector filtering method is applied to disaggregate the uncategorised combined event into one base sample and several sub samples, where the term "sample" is used to refer to the products obtained from the separation process before the classification. Once these samples are assigned to their proper categories, they are called "events". This analysis section includes two layers. The HMM method is applied to the sub samples to determine whether they are actual complete single events or just parts of other events within the combined event. At this stage, to achieve a reliable decision related to the sub event judgment, some pre-determined criteria are incorporated into the existing HMM model. The criteria are the direct outcomes from an intensive statistical study on the whole collected database, which reflects the true user's behavior on different types of water end-use categories. The products obtained after the first layer analysis are the actual, already- classified, single events, and sometimes some additional unclassified sub samples, which do not satisfy the threshold criteria to be assigned to any particular water end-use category. These undetermined samples are then passed through the second layer analysis which is similar to the first one. The only difference between Layer 1 and 2 is that all products achieved after the separation process in Layer 2 (both sub and base samples) would be classified using criteria applied for sub event. The unclassified samples after sub-event Layer 2 analysis, where they exist, are considered as parts of the original base event and, therefore, are returned to that base event at the same time index it has achieved prior to the separation process.

A base event, as previously defined, is the longest single event within the combined event. However, in the second stage of the analysis, the base sample, achieved after the initial separation process, remains problematic, that is, whether it is a single event or another combined event. This uncertainty arises because it is just the remaining product after small or spiky sections are taken away from the original combined event. To tackle this issue, the subjected base sample is dissected into many smaller parts, using the same filtering technique, for further analysis. The outcome of the second stage analysis, following the HMM classification process, is a classified a single base event, with the potential for other classified sub events, where they exist. 
Once the model is completely developed, the verification process follows, which involves testing on 50 independent combined events. The technique verification and result discussion are performed in Section 9 - Model verification.

\section{[Insert Figure 4]}

\section{Combined event separation process}

The first required step in the combined event classification analysis is to separate the subjected event into several smaller parts as displayed in Figure 7. The flow data records the water usage; therefore, the flow rate changes (gradients) indicate a device is switched on or off. A modified gradient vector filtering method is developed to allow the analyst to dissect a combined event to any desired level. This technique plays a fundamental role, in conjunction with the other analytical procedures, to help achieve the separation performance.

The principle of this technique is based on an examination of the gradient change, alongside the event sample, to make different leveling decisions. The method derivation can be explained as follows:

Given a combined event sample, whose flow rate is demonstrated as a vector $\boldsymbol{a}=$ $\left(a_{1}, a_{2}, \ldots a_{j} \ldots, a_{m}\right)$ of length $m$, the gradient of vector $\boldsymbol{a}, \boldsymbol{g}=\left(g_{1}, g_{2}, \ldots g_{j} \ldots, g_{m-1}\right)$, is defined as :

$$
g_{j}=\frac{\left(a_{j+1}-a_{j}\right)}{d t}, \quad 1 \leq j<m
$$

where $j$ is the sampling index, $a_{j}$ is the water flow rate, expressed in terms of litre per minute recorded at time $t_{j}$, and $d t$ is the sampling interval ( $\left.d t=t_{j+1}-t_{j}\right)$. The increase of flow rate gradient indicates the occurrence of a new water use, while the decrease of flow rate implies the completion of a water use. However, due to the possible fluctuation of water pressure in the main, or the intentional flow rate adjustment during the water consumption from the user, the gradient of one event could be unstable, which leads to the misclassification of this event. To overcome this problem, the proposed filtering method is applied to help remove these confusing variations during the analysis.

The main objective is to determine the period (i.e. a series of data points) during which the flow rate fluctuations are not due to the starting or ending of a water-use. The task is carried 
out by setting a criterion for decision making. Given $l$ as the desired filtering threshold, the filtering process is performed on an event section $t_{j} \leq t \leq t_{k},(j<k)$, only if $\left(\forall g_{n} \in \boldsymbol{g}\right)$ and $(j \leq n \leq k)$, all $\left|g_{n}\right|<l$. The new flow rate $\left(a_{n}^{\prime}\right)$ for this period is set to the average flow rate as:

$$
a_{n}^{\prime}=\frac{1}{k-j+1} \sum_{n=j}^{k} a_{n} \quad(j \leq n \leq k)
$$

If the flow rate gradient is greater than the filtering threshold $l$, it would be considered as a new event's starting or completion.

As defined in the prior section, a combined event comprises of one base event and other sub events. In relation to their relative position, the sub event could overlap the base event at three different situations: (i) the sub even starts and finishes earlier than the base event; (ii) the sub even starts later, but finishes earlier than the base event; (iii) the sub even starts and finishes later than the base event. Given two random events, their possible overlapping sections are indicated in Figure 5.

\section{[Insert Figure 5]}

Therefore, in order to separate the sub samples from the original combined event, an examination should be undertaken in these three sections. Figure 6 illustrates a typical combined event separation process. In the first step, the aim is to find out whether there is any sub event starting earlier or finishing later than the base event. At the finishing time $\left(t_{k}\right)$ of a combined event, if the flow rate drop $\left(a_{k-1}-a_{k}\right)$ at the end of a combined event is approximate to the last flow rate rise $\left(a_{m-1}-a_{m}\right)$, i.e. $a_{k-1}-a_{k} \approx-\left(a_{m-1}-a_{m}\right)$ then it is very likely that there is a sub event clamped between $t_{m} \leq t \leq t_{k}$. The same principle can also be applied on the starting phase to detect a sub event in that zone. In the example shown in Figure 6, no sub event is found in the above mentioned zones; however, a typical example for this scenario is presented in Section 8.

Given an original combined event as displayed in Figure 6a, once all the sub events occurring at the two ends of the combined event are identified and removed, the next step is to strip out the other samples located within the left-over combined event. 
The second step in this separation process is to determine the gradient vector of the remaining combined event using Equation (1). Then, the above mentioned gradient vector filtering threshold $l$ is used to filter out the flow rate fluctuations. It should be noted that the filtering method developed for this study only appears in this step to level the gradient vector of the left-over combined event. A range of threshold values for $l$ from 0.05 to $0.85(\mathrm{~L} / \mathrm{min} / \mathrm{min})$ have been tested and value of $l-0.2 \mathrm{~L} / \mathrm{min} / \mathrm{min}$ is adopted as it yields the highest overall recognition accuracy for the model. The leveled gradient vector is shown in Figure 6c.

\section{[Insert Figure 6a]}

\section{[Insert Figure 6b]}

\section{[Insert Figure 6c]}

Based on the filtered gradient vector, the starting and ending moment of each sub sample for separation is determined by finding the point where the gradient vector changes from zero to a positive value (the starting point of a process), and the point where the gradient changes from a negative value to zero (the finishing point of a process). In Figure 6c, the sub samples, determined by this criterion, are marked as 1 and 2. It should be noted that the separation process using this filtering technique ignores the first phase of the remaining combined event, as found in reality. Indeed, it is very unlikely that many events would start at the same time after stripping off the overlapped sub events at the initial state (as performed in the previous steps).

Once all the starting and ending points of each sub sample have been determined, the removing process can be performed by subtracting those samples away from the base event. The achieved products of this process are displayed in Figure 7.

\section{[Insert Figure 7]}

\section{Sub-event analysis}

Prior to the establishment of an overall methodology for performing the combined event analysis, it is necessary to create category index $i=1,2, \ldots, 8$ representing all the eight enduse categories, with the corresponding order as follows: 1- shower, 2 - faucet, 3 - clothes washer, 4 - dishwasher, 5 - full flush toilet, 6 - half flush toilet, 7 - bathtub, and 8 - irrigation . The main process in Layer 1 is the classification process using HMM with threshold criteria. 


\subsection{Layer 1 classification process using HMM with threshold criteria}

The classification process is to be achieved by employing the HMM method, with the likelihood presented as a vector $\boldsymbol{c}=\left(c_{1}, c_{2}, c_{3}, c_{4}, c_{5}, c_{6}, c_{7}, c_{8}\right)$. The sample will be categorised as $i$ if $c_{i}$ is the maximum element of $\boldsymbol{c}$. The testing of the selected combined events reveals that the utilisation of the HMM alone is not sufficient to deal with such a complex recognition problem, which is shown over low classification accuracy. Therefore, some other additional criteria need to be employed. In the present study, the modified likelihood of one sample $\left(C_{i}\right)$ can be determined using Equation (3).

$$
C_{i}=k_{m, i} k_{r, i} c_{i} \quad i=1,2, \ldots 8
$$

where $i$ represents the corresponding water end-use category, as mentioned above. $k_{m, i}$ and $k_{r, i}$ are the magnified factor and the reduced factor for the end-use category $i$ respectively, and $c_{i}$ is the original HMM likelihood of the tested sample. The determination of the magnified factor $\left(k_{m, i}\right)$ and the reduced factor $\left(k_{r, i}\right)$ is different for each end-use category. The achievement of $k_{m, i}$ and $k_{r, i}$ for the clothes washer, dishwasher and toilet are presented in Section 6.1, while Section 7.1 elaborates the steps used to obtain these parameters for the shower, bathtub and irrigation.

The first step in this analysis is used to classify the already separated sub samples, based on some pre-determined criteria. To perform this task, one proposition is made regarding the possible end-use categories of these sub samples. As discussed previously, via many manual analysis processes, these small samples are found to most likely belong to the following categories $i=2,3,4,5,6$. Therefore, within this classification process, the end-uses of these samples are limited to the above mentioned categories (i.e. one sub sample can be assigned to one of the following types: faucet, clothes washer, dishwasher, full flush toilet, half flush toilet and nothing else). To establish a set of criteria for the classification of each particular category, some preparatory tasks are required. In the present study, the combined event classification is performed after the completion of the single event analysis; therefore, all outcomes achieved in the preceding part are inherited and applied into this analysis module. Table 6 shows the necessary parameters for the clothes washer, dishwasher and toilet categories, achieved from the single event classification process, when considering any particular home.

\section{[Insert Table 6]}


With the already classified clothes washer, dishwasher and toilet events achieved from the single event analysis (when investigating one particular home), it is possible to determine the typical flow rate of those clothes washer and dishwasher events; it is also possible to determine the typical volume of the toilet events to be used as the representative physical parameters for that home.

When using the HMM technique for the pattern matching problem in this study, the sample is assigned to the category which has the maximum value among $\left(C_{1}\right)$ to $\left(C_{8}\right)$. There are five categories to be classified in this analysis, namely: the faucet (tap), clothes washer, dishwasher, full flush and half flush toilet. As a consequence, the value of $C_{1}, C_{7}$ and $C_{8}$, which illustrates the integrated possibility of this sample to be shower, bathtub and irrigation, would be zero. The final HMM likelihood vector, calculated by combining with the magnified factor and the reduced vector for one sub sample, is presented in the form of $\boldsymbol{C}=\left(0, C_{2}, C_{3}, C_{4}, C_{5}, C_{6}, 0,0\right)$.

\subsubsection{Clothes washer event}

In the first layer analysis, to help detect the presence of a clothes washer event underlying a combined event, one criterion is set. This criterion is based mainly on the search for the number of clothes washer or dishwasher events, right before and after the combined event, to work out the probability of having those end-uses in the combined event. In the present study, a range of ten events, prior to and subsequent to, the combined event, are examined. As one clothes wash usually takes at least thirty minutes or more, depending on the user's setting, a long time interval is often expected between each cycle; therefore, it is most likely to find only one or two clothes washer cycle within the searching range of ten events.

In order to establish the probability value for detecting the presence of the clothes washer event, and its relative occurrence position with the combined event, the whole database for the 252 homes was analysed. The analysis outcome is based on a consideration of the range of the ten events, before and after the subjected combined sample. The output shows that, if there is at least one clothes washer event, in front of a combined event in a time series (Case 1 ), the probability of having another one in the combined one is $\left(p_{3,1}=36.4 \%\right)$. In the case of the clothes washer event being detected immediately after the occurrence of the combined event (Case 2$)$, the probability now is $\left(p_{3,2}=57.2 \%\right)$. Finally, if one combined event is 
enclosed by two clothes washer events (Case 3), $\left(p_{3,3}=92.6 \%\right)$ makes it certain that more clothes washer samples would be found in the combined event. These probabilities are transformed into the magnified factor to include in the clothes washer HMM likelihood.

As mentioned previously, $c_{3}$ is the HMM probability that the subjected sample is assigned to the clothes washer. This value can be modified by incorporating a magnified factor $k_{m, 3}$ to reflect the likelihood of a variation when there are a certain number of clothes washer events found in front of, and behind, the subjected combined event. The magnified factor $k_{m, 3}$ for the clothes washer can be calculated as:

$$
k_{m, 3}=1+p_{3, j}
$$

where $j=1,2,3$ representing Cases 1,2 and 3 .

The values of $\left(k_{m, 3}\right)$, for different cases, are determined by adding the increase in the probability of finding the clothes washer event $\left(p_{3}\right)$ to the original factor of one. The selection of these magnified factors is proved to be effective for this particular study, demonstrated in the verification process in Section 9. In this study, $k_{m, 3}$ is equal to 1.364, 1.572 and 1.926, for case 1,2 and 3, respectively.

However, the verification process has been proved that, to boost the separation accuracy, another criterion should be established and combined with $k_{m, 3}$. All the washing machines perform under a pre-set mechanical process, which results in a fairly constant flow rate for all cycles; therefore; for a sample to be recognised as a clothes washer event, its flow rate must stay within a certain limit of the typical flow rate for the currently used washing machine. In this case, a reduced factor, $k_{r, 3}$, is obtained to take into account the difference in sample flow rate, with the typical flow rate of the subjected washing machine, which can be achieved from a single event analysis process. The achievement of this factor is performed through the analysis of 8975 classified clothes washer samples (from 252 homes), collected to facilitate this study.

By finding the variation between the flow rates of all the clothes washer events, from one particular home, with the typical flow rate of the washing machine, these differences are assigned to four ranges: 0.5 to 1.5 (L/min) (Case 1), 1.5 to $2.5(\mathrm{~L} / \mathrm{min})$ (Case 2) , 2.5 to 3.5 (L/min) (Case 3), and greater than 3.5 (L/min) (Case 4). This process is repeated 252 times, for all households, to achieve the total number of samples sorted into each case. The findings 
reveal that 7990 clothes washer events (89.08\%) have the flow rate difference in the range of 0.5 to $1.5(\mathrm{~L} / \mathrm{min})$ compared to the typical flow rate. The percentages for cases 2,3 and 4 are 5.28\% (474 samples), 3.31\% (297 samples) and 2.33\% (214 samples), respectively.

If $q$ is the most frequent flow rate of the currently tested sample, $d_{q}$ is the absolute difference between $q$ and $q_{t, 3}$, the typical clothes washer flow rate of the surveyed home, then the reduced factor $\left(k_{r, 3}\right)$ obtained is $0.8908,0.0528,0.0331$, and 0.0233 , for Cases $1,2,3$ and 4 , respectively.

\subsubsection{Dishwasher event}

For the dishwasher event classification, the determination of the magnified factor $\left(k_{m, 4}\right)$ and the reduced factor $\left(k_{r, 4}\right)$ are similar to that of the clothes washer. The magnified factor $\left(k_{m, 4}\right)$, which demonstrates the probability of having a dishwasher event within a combined event, is achieved through the analysis of the 1109 combined events. From the study, it is $\left(p_{4,1}=52.6 \%\right)$ obvious that there is the presence of at least one dishwasher event within range of 10 events before the subjected combined event (Case 1). If there is a dishwasher event detected within the range of 10 events after the combined event, and none of them is found in front of the combined event, the probability of finding one event within the combined event is $\left(p_{4,2}=33.2 \%\right)$ (Case 2$)$.

In the last scenario, if one combined event is clamped by two dishwasher events, both in front of it, and behind it, the probability in this case occurring is $84.2 \%$ (Case 3). With the possibility of finding the dishwasher event within the combined event based on its relative occurrence position; the magnified factor $k_{m, 4}$ for the clothes washer can be calculated using equation $5 ; k_{m d}$ is equal to $1.526,1.332$ and 1.842 , for cases 1,2 and 3 , respectively.

$$
k_{m, 4}=1+p_{4, j}
$$

where $j=1,2,3$ representing Cases 1,2 and 3 .

The reduced factor $k_{r, 4}$ for the dishwasher classification is also achieved using the same process as used for the clothes washer. A dataset of 4877 classified dishwasher events is examined to determine this parameter, which considers the difference between the subjected sample flow rates with the dishwasher typical flow rate from all 252 homes. The values of 
$k_{r, 4}$ are obtained, namely: $0.9426,0.0335,0.0133$, and 0.0106 for the four ranges of 0 to 1.5 , 1.5 to 2.5 , 2.5 to 3.5 , and greater than $3.5(\mathrm{~L} / \mathrm{min})$ respectively.

\subsubsection{Toilet event}

In terms of the full flush and half flush toilet recognition, only the reduced factor is applied $\left(k_{r, 5}\right.$ and $\left.k_{r, 6}\right)$, which reflects the volume difference of the tested sample with the typical full flush and half flush toilet volumes of the surveyed home. In a similar way to the criterion of the flow rate difference for the clothes washer and the dishwasher recognition, the sample can be classified as the toilet, if its volume is within the allowable limit of the cistern volume for the full flush event and the half cistern volume for the half lush event of the currently used toilet. Through the examination of the 23861 toilet events (i.e. both full flush and half flush toilet), it is revealed that 15014 samples (62.92\%) are manually classified as the toilet, although their volume differences range from 0.5 to 1.5 litres compared with the typical toilet volume at their homes (Case 1).

For the difference in the range of 1.5 to 2.5 (Case 2), 2.5 to 3.5 (Case3), 3.5 to 15 (Case 4), and greater than 15 litres (Case 5), the number of achieved samples are 3693 (15.48\%), 3095 (13.07\%) and 2509 (8.63\%), respectively. If $v_{s}$ is the volume of the currently tested sample, $d_{v}$ is the volume absolute difference between $v_{s}$ and $v_{t, 5,6}$, the typical toilet volume of the surveyed home, then the reduced factor $k_{r, 5}$ and $k_{r, 6}$ for the different values of $d_{v}$ will be achieved as $0.6292,0.1547,0.1308,0.0863$ and 0 , for Case 1 to Case 5, respectively.

\subsubsection{Threshold establishment}

The subjected samples in this analysis process are achieved by removing the spiky sections from the original combined event using a subjective separation process; therefore, it is still uncertain whether these sub samples are the actual single events or only parts of a base event. To answer the question relating to this issue, a threshold value is set for the decision making. This boundary for an end-use category was the HMM likelihood value $b$. Thus, the major percentage $\left(p_{s}\right)$ of the sample size (e.g. $p_{s}=50 \%, 60 \%$ or $70 \%$, etc.) classified to this particular end-use has to have a minimum HMM score of $b_{i}$ for category $i$. The aim of this step is to find a vector $\boldsymbol{b}=\left(b_{1}, b_{2}, b_{3}, b_{4}, b_{5}, b_{6}, b_{7}, b_{8}\right)$ which comprises the threshold values for all the end-use types. To find the value for $\boldsymbol{b}$, an analysis of the 78843 unclassified samples, from the 252 homes, is performed using the existing HMM model, which was 
applied in single event analysis. The number of samples classified for each category is summarised in Table 7:

\section{[Insert Table 7]}

For each end-use category dataset, the likelihood of all the samples is determined using the HMM method. If these likelihood values are sorted in descending order, then $b$ is the minimum HMM score of the first $\left(p_{s} \%\right)$ of the likelihood values. There are eight different water end-uses in this analysis; therefore, vector $\boldsymbol{b}$ contained the eight threshold values of all the categories required. The present study employed an iterative method for the range of $p_{s}$ varying from $40 \%$ to $90 \%$. The corresponding vector $\boldsymbol{b}$, which results in the highest recognition accuracy during the verification process, is adopted as the final threshold values for all the end-uses. Over several trials, the value for $\boldsymbol{b}$ at $p_{s}$ of $73 \%$ is achieved (as shown in the Table 7).

The achieved vector $\boldsymbol{b}$ implies that the top $73 \%$ of 6175 shower events and 4389 dishwasher events have a minimum likelihood of 0.000267 and 0.0015148 , respectively. With the established criterion for each end-use category, if any particular event is already assigned to a class, based on the HMM method, if its likelihood is less than the threshold value for that particular class, then that event still remains unclassified, and will be put aside for further analysis.

With all the criteria established to be incorporated into the HMM method, the sub event classification is now ready. The final likelihood of one sample being categorised, as the faucet, clothes washer, dishwasher, full flush toilet or half flush toilet, is determined, as presented in Table 8.

\section{[Insert Table 8]}

\subsection{Second layer sub-sample analysis}

The next analysis stage aims to classify an undetermined sub sample into appropriate end use category. The first task to be undertaken in this stage is to break down the subjected undetermined sample into its respective smaller sample elements, which are named "secondary sub samples and base sample”, using the proposed filtering method. All products achieved from this separation process will be categorised using the HMM method along with 
the subsequent threshold value criterion. The outcome achieved from this classification can fall into one of the following cases:

i. Some of the secondary sub samples are assigned to particular end use categories and some still remain uncertain due to the failure to meet the threshold values.

ii. All secondary sub samples are successfully assigned to their appropriate water end use categories.

iii. All secondary sub samples still remain undetermined.

The first case implies that the original undecided sub sample is actually a combination of some single events with parts of the original base event. This conclusion can be explained based on the extraction of classified single events in the subjected sub sample, and undetermined secondary sub samples which are parts of the actual base event. In this case, all remaining uncertain secondary sub samples would be returned to the original base sample at the same time index as it was before the separation process. In the second case where all secondary sub samples are assigned to different end use categories, then it could be inferred that the undetermined sub sample is actually a combination of many other single events. In the third case, if all separated secondary sub samples fail to be classified into any end use category, it is likely that they are all parts of the actual base event, and they would be returned to the base sample for further analysis.

A limitation of this process is that there is small probability that the actual single events underlying in the undecided sample are sometimes recognised as parts of the original base sample, and vice versa due to the similar shape and characteristics. Therefore, a perfect classification for this layer analysis is unable to be achieved. The effect of this issue is the drop in the final recognition accuracy, which is discussed later in the verification process.

\section{Base-event analysis}

Once all the sub events are fully classified, the final step in this combined event study is to analyse the base sample. The base sample is the product obtained after removing all spiky samples from the original combined event after the initial separation process. As explained in the previous section, via many intensive analysis processes on the collected data, it is revealed that the majority of the base events are formed by only one, or a combination, of the following end-use categories: shower, bathtub, long irrigation, and full flush toilet. The procedure to this type of event is similar to that for the sub event. Firstly, the proposed filtering method (Section 5) is used to separate the primary base sample into many smaller 
secondary sub samples, and a new secondary base sample. Once this step is finished, the HMM, which incorporates some pre-defined base-event analysis criteria, is followed to help with the recognition of all the new sub samples. However, it should be noted that in this analysis, the possible end-uses for the secondary sub samples in the base event analysis is limited to the shower, bathtub, irrigation and toilet. Additionally, the likelihood vector of one sample is in the form of $\boldsymbol{c}=\left(c_{1}, 0,0,0, c_{5}, 0, c_{7}, c_{8}\right)$. The criteria applied to the HMM (i.e. the magnified and reduced factors) are discussed in detail for shower and bathtub end-uses.

\subsection{HMM with threshold criteria for base samples}

\subsubsection{Shower}

For the formulation in Section 6.1, the statistical study of the shower end-use find that about $87 \%$ of all the shower events have a volume greater than 7 litres (Case 1), 7.7\% in the range of 6 to 7 litres (Case 2), 3.8\% in the range of 5 to 6 litres (Case 3), while 1.5\% of the samples have a volume less than 5 litres (Case 4) (Nguyen et al., 2013a). It can be inferred that if any sample has a volume less than the lower limit of 5 litres, then it would be less likely to belong to shower category. The reduced factors $\left(k_{r, 1}\right)$ for the shower event are obtained as $1,0.077$, 0.038 and 0.015 , if the volume of the tested sample falls into Case 1,2,3 and 4, respectively.

\subsubsection{Bathtub}

In terms of the bathtub, the duration of the usage is the governing characteristic, which requires further attention. One of the important findings from the analysis of the bathtub dataset is that $91 \%$ of the bathtub events have a length greater than 4 minutes (case 1), $7.2 \%$ in the range of 3 to 4 minutes (Case 2), 1\% in the range of 2 to 3 minutes (Case 3), and 0\% if the duration was less than 2 minutes (Case 4) (Nguyen et al., 2013a). From these findings, a corresponding reduced factor $\left(k_{r, 8}\right)$ is applied to the HMM score of the subjected sample in consideration of the length of time for the event. The values of $k_{r, 8}$ are adopted as $1,0.072$, 0.001 and 0 for the four corresponding cases.

\subsubsection{Irrigation and full flush toilet}

For the irrigation event, there is no dominant distribution in the characteristics, such as duration, flow rate or volume, as this type of end-use is subjected to the user's behaviour. As a result, the primary HMM score is adopted as the final likelihood for this type of end-use, and the magnified factor $\left(k_{m, 8}\right)$ and the reduced factor $\left(k_{r, 8}\right)$ are adopted as 1 . In terms of the 
full flush toilet, $k_{m, 5}$ and $k_{r, 5}$ are readopted as the criteria for this end-use in the analysis process.

With all the criteria incorporated into the HMM method, the new sub sample classification is now ready. The final likelihood of one sample being categorised as shower (1), full flush toilet (5), irrigation (7) and bathtub (8) is determined (see Table 9). Once all the sub samples are assigned to the different categories, the last step is to check against the threshold value. If the final HMM score of the sample is less than the corresponding threshold value, then it could be confirmed as part of the original base event, and is added to the base sample at the same time index as before.

\section{[Insert Table 9]}

The final step in the combined event analysis is to classify the remaining secondary base sample, which is assigned to the shower, bathtub, irrigation or toilet. At this step, the HMM, with the magnified and reduced factors, is employed to perform the required task. However, unlike all the previous recognition processes, the process of checking against the threshold value is skipped, with the score achieved from this technique being adopted as the final likelihood for the decision making. Indeed, it is found during the analysis that the overall accuracy does not show any change if the secondary base sample is separated and further analysed when failing in threshold value checking; therefore, with the suggested procedure, the current model can still guarantee the reliability and save significant processing time.

\section{Combined event analysis example}

For a more comprehensive understanding of the overall study, the proposed technique is performed on one typical combined event collected to explain, in detail, how each step is applied. The original event's details are extracted directly from the user's diary (presented in Table 10 below).

\section{[Insert Table 10]}

Some additional information in the household is also provided as:

- One clothes wash started from 7:30 am and finished at 8:13 am 
- No dish washing in the morning

- Toilet cistern volume: $7.0 \mathrm{~L}$

From the given information, a manual analysis was performed to separate this event; the outcome is shown in Figure 8 below:

\section{[Insert Figure 8]}

\subsection{Combined event separation process}

The ultimate aim for this example is to apply the proposed technique to achieve the disaggregated single events matching the ones shown in the above figure. With the event sample presented as $\boldsymbol{a}=\left(a_{1}, a_{2}, \ldots a_{j} \ldots, a_{m}\right)$, where $m=58$. As introduced in Section 5 , the first step is to identify whether any sub event occurs before the base even starts or completes after the base event finishes. As can be seen from Figure 9, no sub event is found during the initial phase, but a sub event displayed by the blue line is identified and separated from the original event in the final phase.

\section{[Insert Figure 9]}

The second task is to strip out all the sub samples, which completely lies on top of the remaining base one. This objective is accomplished by firstly calculating the gradient vector $\boldsymbol{g}$ of the remaining combined sample using Equation (1). The required vector is shown in Figure 10 below:

\section{[Insert Figure 10]}

At this point it is important to remember that the aim of finding the gradient vector is to determine the period for each sub sample. Based on the achieved gradient vector, the task is undertaken by looking for the moment when each sub sample starts (the rise of the original event's flow rate, which is presented over the gradient change from zero to a positive value) and finishes (flow rate drop displayed over the gradient change from a negative value to zero). To perform this task, the developed filtering method is employed to help level out the gradient vector. As mentioned in the previous section, the value $l$ of $0.2 \mathrm{~L} / \mathrm{min} / \mathrm{min}$ is recommended for the filtering purpose of this particular study. The filtered vector is displayed in Figure 11. 


\section{[Insert Figure 11]}

With all the identified starting and finishing points of the underlying sub samples, the second separation task is now ready. The complete products of the combined event breaking down process are shown in Figure 12.

\section{[Insert Figure 12]}

\subsection{Sub event recognition}

Figure 13 shows two sub samples extracted from the original combined event, which are named "Sub 1" and "Sub 2".

\section{[Insert Figure 13]}

In Layer 1 analysis, all the sub samples are passed through the HMM recogniser, with the output categories restricted to faucet, clothes washer, dishwasher and toilet. The information, presented in Table 11, is given by the surveyed home to enable the combined event analysis.

\section{[Insert Table 11]}

It should be noted that when the whole autonomous flow trace analysis system is completed, the detection of the above physical characteristics could be achieved automatically. By applying the HMM method, in addition to the adopted reduced and magnified factors (shown in Section 6.1) on each sub sample, the final HMM likelihood for each of them is obtained. At the end of this process, Sub 1 is classified as half flush toilet, and Sub 2 still remains undetermined due to the failure in threshold value checking (Appendices A1 and A2). Thus, a second layer analysis is required to further examine the undetermined sub sample 2.

Within this analysis, the subjected undetermined sample is broken down again. The separated products are named "Sub 3" and “Sub 4", and are displayed in Figure 14.

\section{[Insert Figure 14]}


With the availability of two new sub samples, the recognition process using the HMM on each of them is ready. From the analysis, Sub 3 and Sub 4 are classified as half flush toilet and faucet respectively (Appendices A3 and A4). This outcome is identical to what was written in the collected user's diary.

\subsection{Base sample analysis}

The final task in this study is the recognition of the base sample, which is presented in Figure 15 below.

\section{[Insert Figure 15]}

As previously discussed, the possible end-uses of the base event in this study are limited to the shower, bathtub, long irrigation and full flush toilet, as they are long enough to allow the overlapping with other events. In the present analysis, the HMM, in combination with some other pre-determined criteria for bathtub and shower, is applied to determine the final likelihood of the subjected sample. From the HMM final score (Appendix A5), the base sample is eventually classified as the shower, which matches the one given in the user's dairy.

In summary, with the achieved classified events, it can be stated that the proposed method is effective in dealing with the problem of disaggregating a combined event into different components. In this illustrative example, only a tiny faucet event is missed as it was considered as a part of the based shower event. This problem is insignificant and understandable as, in reality, the flow rate of most events are unstable due to the fluctuation of water pressure, or the adjustment of the water user. The volumes of these missed events are minor compared to that of the original combined event; therefore, the final recognition accuracy of the overall study is not really affected. However, to confirm the efficiency of the proposed disaggregation technique, more testing should be undertaken. The next section introduces a comprehensive verification process of the final algorithm on various types of common combined events.

\section{Model verification}

\subsection{Combined event classification accuracy}

The model is verified using another independent 50 combined events, which are basically divided into three categories with the increasing level of complexity. 
Type 1 of the independent combined events includes two events which occur simultaneously. The longer one of these two events plays as the base event, while the remaining one is considered as the sub event. This is the simplest event combination in reality; therefore, in the present study, only five samples of this type are collected to facilitate the testing process.

Type 2 of the independent combined event comprises a group of concurrent events, in which the longest event is the base one and all other smaller events laying on top of this large event are sub events. This is the most common type of event combination, and 35 independent samples are used to serve the verification.

The last, and the most complex, type of combined event is the one which comprises two overlapped layers. A typical sample of this problem is shown in the illustrative example in Section 8. For example, one combined event includes three components; the longest one lies in the bottom, and plays as the base event. Some simultaneous events, located right above the base one, are considered as the first overlapping layer. In the second overlapping layer, some other events will occur on top of the sub events in layer 1 . There are 10 samples of this type collected for the present study. Figure 16 shows examples of each type of the independent combined events verified in the present study.

\section{[Insert Figure 16a]}

\section{[Insert Figure 16b]}

\section{[Insert Figure 16c]}

The efficiency of the proposed technique is thoroughly verified by examining all aspects of the independent samples. In the present study, two accuracy indices are achieved to give the reader a broad overview of how effective the recommended method is in analysing each type of combined event, and one accuracy index obtained for the recognition of the particular water end-use category. For the individual combined event examination, the method effectiveness is illustrated over the accuracy in terms of the number of events, $A_{N}$. This is achieved by determining the ratio between the numbers of correctly classified single events, over the total events, within the combined one. The accuracy, in terms of volume, $A_{V}$, aims to find the ratio between the correctly classified volume over the actual volume of each single 
event, within the combined one. These two indices are clearly presented in Table 12 for the three different types of event combinations. A detailed description and accuracy of each tested event can be found in Appendices A6, A7 and A8.

\section{[Insert Table 12]}

From Table 12, it can be seen that all Type 1 combined events are accurately separated and identified. The accuracy of $98.9 \%$, in terms of volume, is obtained because during the separation process, the starting and ending points of each component single event were not perfectly determined. This result leads to the slight difference in the volume of the separated event compared to that of the actual single event. The accumulation of all the volume variations results in the drop of the average accuracy for this type of combined event.

The great separation accuracy achieved for this event combination becomes a good preparation for the testing of more complicated combined events. Over many manual end-use studies, combined event Type 2 is found to be the most common event combination found in reality, which is comprised of one large base event and several other sub events; therefore, the testing on this type of sample is the main focus for this verification process. Within 35 independent samples of this type, there are 223 sub events, spreading over the following enduse kinds, such as: tap, toilet, clothes washer and dishwasher; and 35 base events belonging to the shower, irrigation and bathtub end-use. The results from the proposed technique show that six base events are misclassified (accuracy of 82.9\%), which substantially reduces the accuracy, in terms of volume, for those testing samples, as these base events cover the majority of the sample volumes. In terms of the sub event recognition, 181 out of the 223 sub events are placed into their correct category (81.2\%). The outcome shows that the method is highly efficient when dealing with this type of sample. In summary, $81.4 \%$ of total events extracted from the 35 samples have been accurately put into the correct groups, while $82.6 \%$ of the total volumes have been properly sorted.

The high recognition accuracy attained for this type of combined event has the potential to extend the proposed technique for more complicated event combinations. The next level of the combined event that is tested includes two overlapping layers, as introduced earlier in this section. For this type of event, 10 samples (i.e. 65 sub events, ranging from tap, toilet, clothes washer, dishwasher, and bathtub, to shower), and 10 base events (of the shower, bathtub and 
irrigation) are collected and verified. Unlike type 1 and 2, this type of event allowed a combination of many large events (such as the shower, irrigation and bathtub); therefore, the longest event is identified as the base event, and all shorter events, even irrigation, bathtub or shower, are identified as sub events. Surprisingly, the accomplished accuracy, in terms of the number of events for this type, is even higher than that of type 2 (82.7\% compared to $81.4 \%)$, and the accuracy for the volume is almost the same (82.4\% compared to $82.6 \%)$. Thus, the proposed method is effective in analysing most types of combined events, from the easiest one of two overlapping events to the most complicated sample-two overlapping layers of many events.

However, for a more comprehensive understanding of how the technique performed on each type of end-use, Table 13 is established to indicate the accuracy achieved for each particular end-use for all three tested types:

\section{[Insert Table 13]}

The table shows that the disaggregation accuracy is over $75 \%$ for all water end-uses, with the highest, $89.7 \%$, for clothes washers, and the lowest, $76.5 \%$ for irrigation. Due to their similar patterns, the shower, bathtub and irrigation events are often misclassified, which dramatically bring the accuracy down for these end-uses. To overcome this problem, it is recommended that more information should be provided on the available types of end-use presented in the surveyed home (e.g. the survey home does or does not irrigate, etc.). The right identification of the base events makes a significant contribution to the overall system accuracy, as their volumes are often completely dominant all other sub events. In terms of the sub event, the high classification accuracy of the clothes washer, dishwasher and toilet events are proved.

The incorporation of the magnified factors and reduced factors into the HMM likelihood of these end-uses is very effective for this type of problem. Within this verification process, most of the misclassified toilet events are put into the faucet group, as their patterns are distorted due to the pressure loss occurring when many events occur concurrently. Moreover, unlike traditional full flush and half flush toilets, the water pattern of some new toilet models is not constant anymore, as the user can decide the amount of water to be released. The combination of these two issues has imposed a difficulty on the classification of a toilet event underlying a combined event. The performance on the faucet event is impressive, as $87.1 \%$ of 
the overall faucet samples are accurately classified. This notably high accuracy is due to the fact that most faucet patterns are unpredictable; however, in reality, they usually have relatively small volumes, which is the main characteristic for the system to recognise. In addition, with a huge number of collected faucet events to facilitate this study, the developed HMM classifier is also more effective for the faucet category.

\subsection{Comparison with existing combined event analysis methods}

As mentioned previously, one of the most widely used tools for flow trace analysis in the water industry is Trace Wizard (Beal and Stewart, 2012), which was developed to disaggregate a series of flow signals into different end-use categories. However, the accuracy of this software depends greatly on the reliability of the input parameters, which requires detailed information about the available water end-use (e.g. whether to have irrigation, bathtub, or dishwasher, etc.). The water efficiency, the maximum, minimum and most frequent flow rate of every single end-use device in the surveyed home was needed. The collection of such input data, however, is resource intensive, while the method itself is not feasible for large scale application. The first paper on a single event analysis (Nguyen et al., 2013a) proposed a new method to solve the primary single event classification. The new method's recognition accuracy is shown to far outweigh the Trace Wizard. In terms of the combined event analysis, the highest complexity level that Trace Wizard could manage is the Type 2 event combinations (i.e. a group of simultaneous events with only one overlapping layer); therefore, the very low disaggregation accuracy is often expected when analysing Type 3 event combinations. With its ability to examine the three types of combined events, the newly developed method stands out for being the ideal solution for the combined event analysis. To illustrate the difference between the Trace Wizard and the proposed technique, a further testing process is performed on 50 independent samples, with the outcomes shown in Table 14.

\section{[Insert Table 14]}

As displayed in Table 14, the recognition accuracy achieved for the Type 1 event combination is very high, with 8 out of 10 single events, included in the 5 samples, are assigned to the appropriate category. The two misclassified samples are faucet events, whose volumes are relatively small; therefore, the average accuracy, in terms of volume attained, is almost absolute. However, a considerable difference is shown by the Type 2 event analysis; 
only 166 out of 258 single events are accurately identified; this included 141 sub events and 25 base events. The misclassification of 10 base events, whose volumes are significantly large, brings down the average accuracy in terms of the volume to $65.2 \%$.

The final testing is conducted on the Type 3 combined events, which has gone beyond the ability of the Trace Wizard. In this analysis, all the sub events located in the second overlapping layer are ignored. This action dramatically affects the average accuracy in terms of the number of events. Only 5 out of 10 base events, and 24 out of 65 sub events, are put into the right groups. The result shows that an accuracy of $38.6 \%$ in terms of the number of events and $55.4 \%$ in terms of the volume were achieved. In summary, the average testing accuracy on three different combined event types of $41.6 \%$ and $72.3 \%$, the Trace Wizard is far behind the proposed method. The new method correctly classifies $88 \%$ of the total events and volumes using this technique. This outcome again proves that the newly developed algorithm for the combined event analysis is expected to be widely applied in the future.

\section{Conclusions, limitations and future directions}

The establishment of an integrated water management system, which employs smart water metering, in conjunction with an intelligent algorithm to automate the flow trace analysis process, is becoming more and more feasible. The first fundamental step to extract the single events from the flow rate series, and assign them to appropriate categories, was achieved using a model containing a hybrid combination of HMM and DTW algorithms. This single event disaggregation model is comprehensively described in (Nguyen et al., 2013a). However, combined events are a significant proportion of residential consumption and the goal of having a comprehensive automated pattern recognition model would not be achieved without solving this challenging disaggregation and recognition process. The present study provides a robust event classification process for combined events through applying the HMM, DTW algorithm and gradient vector filtering techniques Model validation testing of 50 independent simultaneously occurring events of increasing combination complexity demonstrated good accuracy. The average disaggregation accuracy achieved through the validation process, both in terms of the number of events and their volume, was $88 \%$.

The main difficulty encountered when dealing with combined event disaggregation is the pattern distortion of all the contributing single events, due to the pressure lost in the pipe, when many events occur simultaneously. The outcome results in a reduction in the overall 
disaggregation accuracy. For example, a distorted toilet or dishwasher event induced by pressure loss has a similar shape to that of a faucet, and may be eventually classified as a faucet event. Collecting and manually classifying the single event components of a much larger sample of combined events will be the focus of future research in order to better under the influence of pressure drop on single event characteristics.

The final analytical stage of the greater study will be to formulate an intelligent self-learning algorithm, which allows the system to characterise the distinct end-use characteristics of any new residential house analysed by the system, by drawing on existing extensive registries of event signature prototypes already established and interpreting these new variant events and accurately assigning them to the prototype registry. Once this algorithm is complete, a user friendly automatic flow trace analysis application will be developed. The application will integrate the already completed single and combined event classification processes, along with the future developed self-learning processes into one comprehensive residential water end use event pattern recognition system. A verification process on samples of independent homes from various urban areas within Australia, and later abroad, will be carried out to confirm the accuracy level of this application for various situational context (e.g. region, dwelling type, etc.).

\section{Model development implications for urban water management}

The model developed in this study is the key element for the building of an integrated water management system which is able to automatically categorise the flow data recorded from water meter into all end-use categories. One application of this system allows for individual consumers to log into their user-defined water consumption web page to view their daily, weekly and monthly consumption tables as well as charts on water consumption patterns for categories of water end use. Average and/or best practice water end use charts can also be provided for similar family types in the suburb or city of the householder so they can see how their consumption compares (i.e. compared to descriptive norms) and address consumption categories of high consumption (e.g. comparably high shower use may entice the homeowner to install a high efficiency shower head). Moreover, cumulative water billing can be updated daily or even hourly, and on-line alarms could be generated to indicate potential causes for excessive water use. This will help consumers to take corresponding water saving actions. 
From an operational perspective, there are significant implications for improving current practices of infrastructure planning and management. The provision of demand and supply data from such a system can assist in urban water system modelling and infrastructure planning through:

- Providing real-time diurnal pattern data of water demands at a household level which will assist with understanding required supply quantities, storage needs, excess supply available for resale or distribution, and discharge volumes;

- Providing better predictive models on wastewater system requirements (e.g. treatment processes, estuarine, marine and river impacts, etc.) through real-time end use data related to prior knowledge on the typical waste constitute materials associated with such uses;

- Better modelling of water and wastewater systems and improved identification of upgrade requirements for stressed infrastructure;

- A comprehensive understanding of the expandability of a particular region (with existing infrastructure) and management of growth based on water demands; and

- Effective priority infrastructure planning and regional planning.

The data from the integrated water management system will also provide significant insight into the development and effectiveness of water demand management strategies at the development scale. Moreover, the application could significantly improve the current decision making relating to the development of Water Demand Management (WDM) strategies as well as provide empirical verification on achieved water savings from already implemented programs. The application of real-time end use data, for both water authorities and consumers, will undoubtedly revolutionise the current ad-hoc approach to WDM, by providing:

- The ability to monitor the effect of enforcement or restriction levels on water consumption;

- The ability to immediately quantify the effect of targeted education programs (e.g. for particular demographics, shower time, rebate program, etc.) on their intended water end use(s);

- The capacity to establish the water savings resulting from implemented engineering applications such as efficient water appliances (e.g. washing machines, shower roses, etc.) and pressure and leakage management; 
- Real time water consumption data provided to water users/customers resulting in an increased level of knowledge and understanding of personal water consumption and how this compares with others; and

- A tool for definitive financial analysis of the cost and water saving benefits of implemented WDM programs, ultimately driving a least cost planning agenda; and

- Easy identification of leakage in households or businesses.

The system will allow for the instantaneous quantification of the effect of WDM strategies on water consumption. This will lead to significant improvement on the development and delivery of such measures, thus closing the loop on demand management strategies. Stewart et al. (2010) also provided a detailed discussion on the benefits of smart metering and high resolution water end use data for enhanced urban water infrastructure planning and management.

\section{References}

Baum, L.E.; Petrie, T., Soules, G., Weiss, N., 1970. A Maximization Technique Occurring in the Statistical Analysis of Probabilistic Functions of Markov Chains. The Annals of Mathematical Statistics 41: 164. DOI:10.1214/aoms/1177697196.

Beal, C., Stewart, R.A., 2012. South East Queensland residential end use study: final report. Technical Report No. 47 for Urban Water Security Research Alliance. Griffith University and Smart Water Research Centre, January 2012.

Beal, C., Stewart, R.A., Fielding, K., 2011a. A novel mixed method smart metering approach to reconciling differences between perceived and actual residential end use water consumption. Journal of Cleaner Production, doi:10.1016/j.jclepro.2011.09.007.

Beal, C., Stewart, R.A., Huang, T.T., Rey, E., 2011b. SEQ residential end-use study. Journal of the Australian Water Association 38 (1), 80-84.

Bhadeshia, H. K. D. H., 1999. Neural Networks in Materials Science. ISIJ International 39 (10): 966-979. DOI:10.2355/isijinternational.39.966.

Bishop, C.M., 1995. Neural Networks for Pattern Recognition, Oxford: Oxford University Press. ISBN 0-19-853849-9 or ISBN 0-19-853864-2

Blokker, E., Vreeburg, J., Van Dijk, J., 2010. Simulating residential water demand with a stochastic end use model. Journal of Water Resources Planning and Management; 136: 19- 26.

Boashash, B., 2003. Time Frequency Signal Analysis and Processing. A comprehensive reference. Elsevier. ISBN 0080443354. 
Cha, S. H.; Tappert, C. C., 2009. A Genetic Algorithm for Constructing Compact Binary Decision Trees. Journal of Pattern Recognition Research 4 (1): 1-13. http://www.jprr.org/index.php/jprr/article/view/44/25.

CSIRO. 2012. SEQ Residential Water End Use Study: Validation Trial of CSIRO End Use Sensor. Urban water security research alliance. Technical report No. 91.

Da, Y., Xiurun, G., 2005. An improved PSO-based ANN with simulated annealing technique. In T. Villmann. New Aspects in Neurocomputing: 11th European Symposium on Artificial Neural Networks. Elsevier. DOI:10.1016/j.neucom.

David, C.H., Yang, Z.L., Hong, S., 2013. Regional-scale river flow modelling using off-theshelf runoff products, thousands of mapped rivers and hundreds of stream flow gauges. Environmental Modelling \& Software 42 (2013) 116-132

Deng, H., Runger, G., Tuv, E., 2011. Bias of importance measures for multi-valued attributes and solutions. Proceedings of the 21st International Conference on Artificial Neural Networks (ICANN). http://enpub.fulton.asu.edu/hdeng3/MultiICANN2011.pdf.

Dorini, G., Jonkergouw, G., Kapelan, Z., Pierro, F., Khu, S.T and Savic, D., 2006. An efficient algorithm for sensor placement in water distribution systems. Proceedings of 8th Annual Water Distribution Systems Analysis Symposium, Cincinnati, Ohio, USA, August 27-30, 2006.

Dürrenmatt, D.J., Gujer, W., 2012. Data-driven modelling approaches to support wastewater treatment plant operation. Environmental Modelling \& Software 30 (2012) 47-56

Eggers, G., Politti, E., Woo, H., Cho, K-H., Cho, H., Benjankar, R. Lee, N-J., Lee, H., 2012. Dynamic vegetation model as a tool for ecological impact assessments of dam operation. Journal of Hydro-environment Research, Special Issue on Ecohydraulics: Recent Research and Applications, 6(2), 151-161.

Ephraim, Y., Merhav, N., 2002. Hidden Markov processes. Information Theory, IEEE Transactions on, 48, 1518-1569.

Froehlich, J., Larson, E., Saba, E., Campell, T., Atlas, L., Fogarty, J., Patel, S., 2011. A longitudinal study of pressure sensing to infer real-world water usage events in the home. Computer Science and Engineering. University of Washington

Froehlich, J.E., Larson, E., et al., 2009. HydroSense: infrastructure-mediated single-point sensing of whole-home water activity. In: Proc. of UbiComp 2009, Orlando, Florida, USA, pp. 235-244 .

Ghahramani, Z., Jordan, M. I., 1997. Factorial Hidden Markov Models. Machine Learning 29 (2/3): 245-273. DOI:10.1023/A:1007425814087.

Glasgow, H.B., Burkholder, J.M., Reed, R.E., Lewitus, A.J., Kleinman, J.E., 2004. Real-time remote monitoring of water quality: a review of current applications, and advancements in sensor, telemetry, and computing technologies. Journal of Experimental Marine Biology and Ecology 300 (2004) 409- 448 
Haykin, S., 1999. Neural Networks: A Comprehensive Foundation, Prentice Hall, ISBN 013-273350-1

Heinrich, M., 2006. Water End-use and Efficiency Project (WEEP) - Final Report, BRANZ Study Report 159, Branz, Judgeford, New Zealand.

Hertz, J., Palmer, R.G., Krogh. A.S., 1990. Introduction to the theory of neural computation, Perseus Books. ISBN 0-201-51560-1

Howell, D. C., 2004 Fundamental Statistics for the Behavioural Sciences, Thompson Brookes/Cole, Belmont, CA.

Jacobs, H. E., 2007. The first reported correlation between end-use estimates of residential water demand and measured use in South Africa. Water SA; 33(4): 549 - 558.

Kowalski, M., Marshallsay, D., 2005. Using measured micro-component data to model the impact of water conservation strategies on the diurnal consumption profile. Water Science and Technology:Water Supply; 5(3-4), 145-150.

Lindim, C., Hayter, E. J., Pinho, J. L. S., Vieira, J. M. P. , 2010. Modeling thermal structure variations in a stratified reservoir. Proceeding of the Fifth Biennial Conference of the International Environmental Modelling and Software Society, Ottawa, Canada, 5-8 July 2010.

Loh, M. and Coghlan, P., 2003. Domestic water use study in Perth, Western Australia 1998 to 2000. Water Corporation of Western Australia.

Mayer, P., DeOreo, W., Towler, E., Martien, L., Lewis, D., 2004. Tampa water department residential water conservation study: the impacts of high efficiency plumbing fixture retrofits in single-family homes. Aquacraft Inc. Water Engineering and Management, USA.

Mead, N., 2008. Investigation of domestic end use. Honours Thesis, Faculty of Engineering \& Surveying, University of Southern Queensland, Toowoomba, Australia.

Murlà. Da, Monistrol. Aa, Poch, M a,b , Sunyer. Dc. 2010. Development of a modular Environmental Decision Support System for the Integrated Management of the Urban Wastewater Cycle at River Basin Scale. Proceeding of the Fifth Biennial Conference of the International Environmental Modelling and Software Society, Ottawa , Canada, 5-8 July 2010.

Muller, M., 2007. Information Retrieval for Music and Motion, Chapter 4 . Springer, ISBN 978-3-540-74047-6

Myers, C. S., Rabiner, L. R., 1981. A comparative study of several dynamic time-warping algorithms for connected word recognition. The Bell System Technical Journal, 60, 1389-1409. 
Nguyen, K.A., Zhang, H., Stewart, R.A., 2013a. Development of an intelligent model to categorise residential water end use events. Journal of Hydro-Environment Research. DOI: 10.1016/j.jher.2013.02.004

Quinn, N.W.T, Ortega, R., Rahilly, P.J.A, Royer, C.W., 2010. Use of environmental sensors and sensor networks to develop water and salinity budgets for seasonal wetland real-time water quality management. Environmental Modelling \& Software 25 (2010) 1045-1058

Rabiner, L., Juang, B., 1993. Fundamentals of speech recognition. Prentice-Hall, Inc., Chapter 4.Rabiner, L. R. 1990. A tutorial on hidden Markov models and selected applications in speech recognition. Readings in speech recognition. Morgan Kaufmann Publishers Inc.

Roberts, P., 2005. Yarra Valley Water 2004 Residential End-use Measurement Study. Melbourne. Yarra Valley Water.

Satish, L., Gururaj, B. I., 2003. Use of hidden Markov models for partial discharge pattern classification. IEEE Transactions on Dielectrics and Electrical Insulation.

Sakoe, H., Chiba, S., 1978. Dynamic programming algorithm optimization for spoken word recognition, Acoustics, Speech and Signal Processing,19 IEEE Transactions on, vol. 26, no. 1, pp. 43\{49, 1978. [Online]. Available: http://ieeexplore.ieee.org/xpls/abs all.jsp?arnumber $=1163055$

Schimak, G., Rizzoli, A., Watson, K. 2010 Sensors and the environment - Modelling \& ICT challenges. Environmental Modelling \& Software.

Shapiro, L., George. S., 1998. Computer Vision. Upper Saddle River, New Jersey: PrenticeHall, Inc. pp. 157-158, 215-216, 299-300. ISBN 0-13-030796-3.

Starner, T., Pentland, A., 1995. Real-Time American Sign Language Visual Recognition From Video Using Hidden Markov Models. Master's Thesis, MIT, Program in Media Arts.

Stewart, R. A., Willis, R., Giurco, D., Panuwatwanich, K., Capati, G., 2010. Web-based knowledge management system: linking smart metering to the future of urban water planning. Australian Planner, 47, 66 - 74.

Storey, M.V., Gaag, B.V.D, Burns, B.P. 2011. Advances in on-line drinking water quality monitoring and early warning systems. water research 45 ( 2011), 741 -747

Tapia, E., Intille, S.S., Larson, K., 2004. Activity Recognition in the Home Using Simple and Ubiquitous Sensors. In: Ferscha, A., Mattern, F. (eds.) PERVASIVE 2004. LNCS,vol. 3001, pp. 158-175. Springer, Heidelberg (2004)

Usländer, T., Jacques, P., Simonis, I.,Watson, K., 2010. Designing environmental software applications based upon an open sensor service architecture. Environmental Modelling \& Software , 25 (2010) 977-987 
White, D.H., Beynon, N., Kingma, O., 2006. Identifying opportunities for achieving water savings throughout the Murray-Darling Basin. Environmental Modelling \& Software 21 (2006) 1013-1024

Willis, R.M., Stewart, R. A., Panuwatwanich, K., Jones, S., Kyriakides, A., 2010a. Alarming visual display monitors affecting shower end-use water and energy conservation in Australian residential households. Resources, Conservation and Recycling. 54(12), 11171127.

Willis, R.M., Stewart, R.A., Williams, P., Hacker, C., Emmonds, S., Capati, G., 2011b. Residential potable and recycled water end-uses in a dual reticulated supply system. Desalination. 272(1-3), 201-211.

Willis, R.M., Stewart, R.A., Giurco, D.P., Talebpour, M, Mousavinejad, A., 2011c. End use water consumption in households: impact of socio-demographic factors and efficient devices. Journal of Cleaner Production (2011) 1-9

Yiee, H.H. and Baskin, L.S., 2011. Use of internal stent, external transanastomotic stent or no stent during pediatric pyeloplasty: A decision tree cost-effectiveness analysis, The Journal of Hydrology, 185(2), 673-681.

Yuan, Y., Shaw, M. J., 1995. Induction of fuzzy decision trees. Fuzzy Sets and Systems 69 pp. 125-139

Zhang, H., Jeng, D.-S., Cha, D., Blumenstein, M., 2007. Parametric study on the Prediction of Wave-induced Liquefaction using an Artificial Neural Network Model, SI 50, Journal of Coastal Research, 374-378.

\section{Appendices}

[Insert Table A1]

[Insert Table A2]

[Insert Table A3]

[Insert Table A4]

[Insert Table A5]

[Insert Table A6]

[Insert Table A7]

[Insert Table A8] 
Figure 1 Schematic illustrating the water end-use analysis process (Beal et al., 2011a)

Figure 2 End use event classification process (Nguyen et al., 2013a)

Figure 3 Single event analysis process (Nguyen et al., 2013a)

Figure 4 Combined event analysis process

Figure 5 Possible overlapping positions of two random samples

Figure 6a Original combined event for method illustration

Figure $6 \mathrm{~b} \quad$ Gradient of the remaining combined sample

Figure 6c Filtered gradient vector

Figure $7 \quad$ Achieved samples after separation process

Figure 8 Actual singles events in the combined one

Figure 9 Separation of sub sample at starting and finishing phase

Figure 10 Gradient of the remaining sample

Figure 11 Filtered gradient of the remaining sample

Figure 12 Products achieved from the separation process

Figure 13 Sub samples achieved from the separation process

Figure 14 Two secondary sub samples achieved from the separation process

Figure 15 Base sample achieved from the separation process

Figure 16a Type 1 independent combined event

Figure 16b Type 2 independent combined event

Figure 16c Type 3 independent combined event 
Figure 1 Schematic illustrating the water end-use analysis process (Beal et al., 2011a)

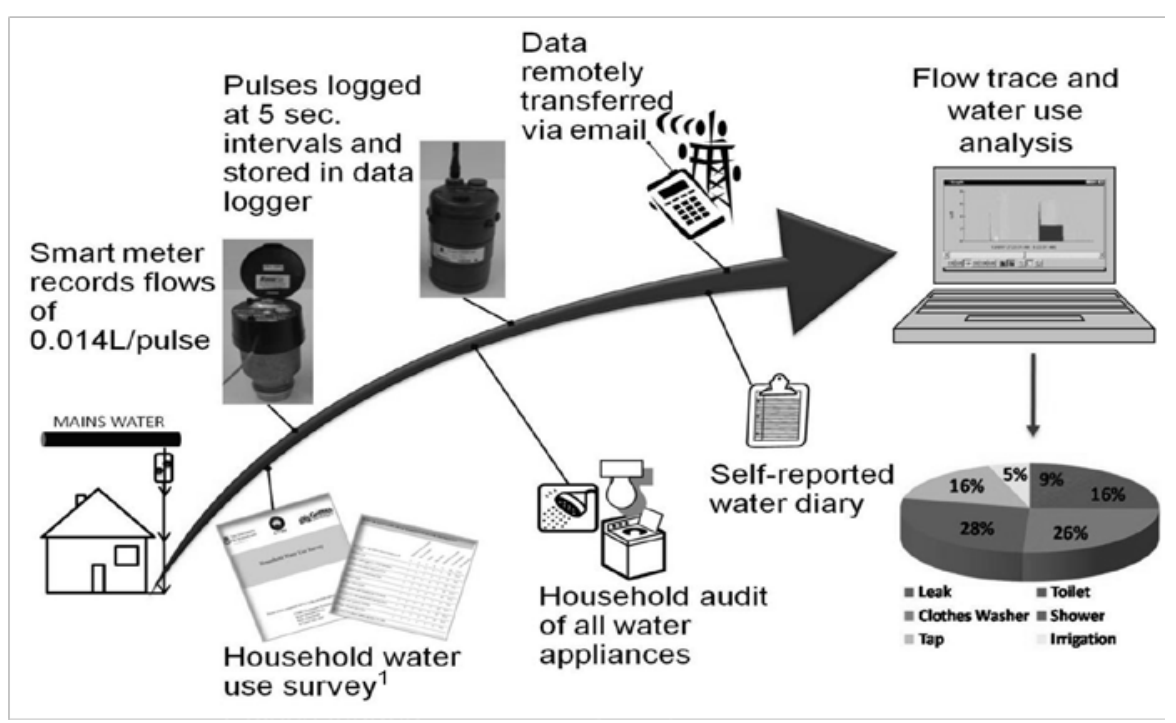


Figure 2 End use event classification process (Nguyen et al., 2013a)

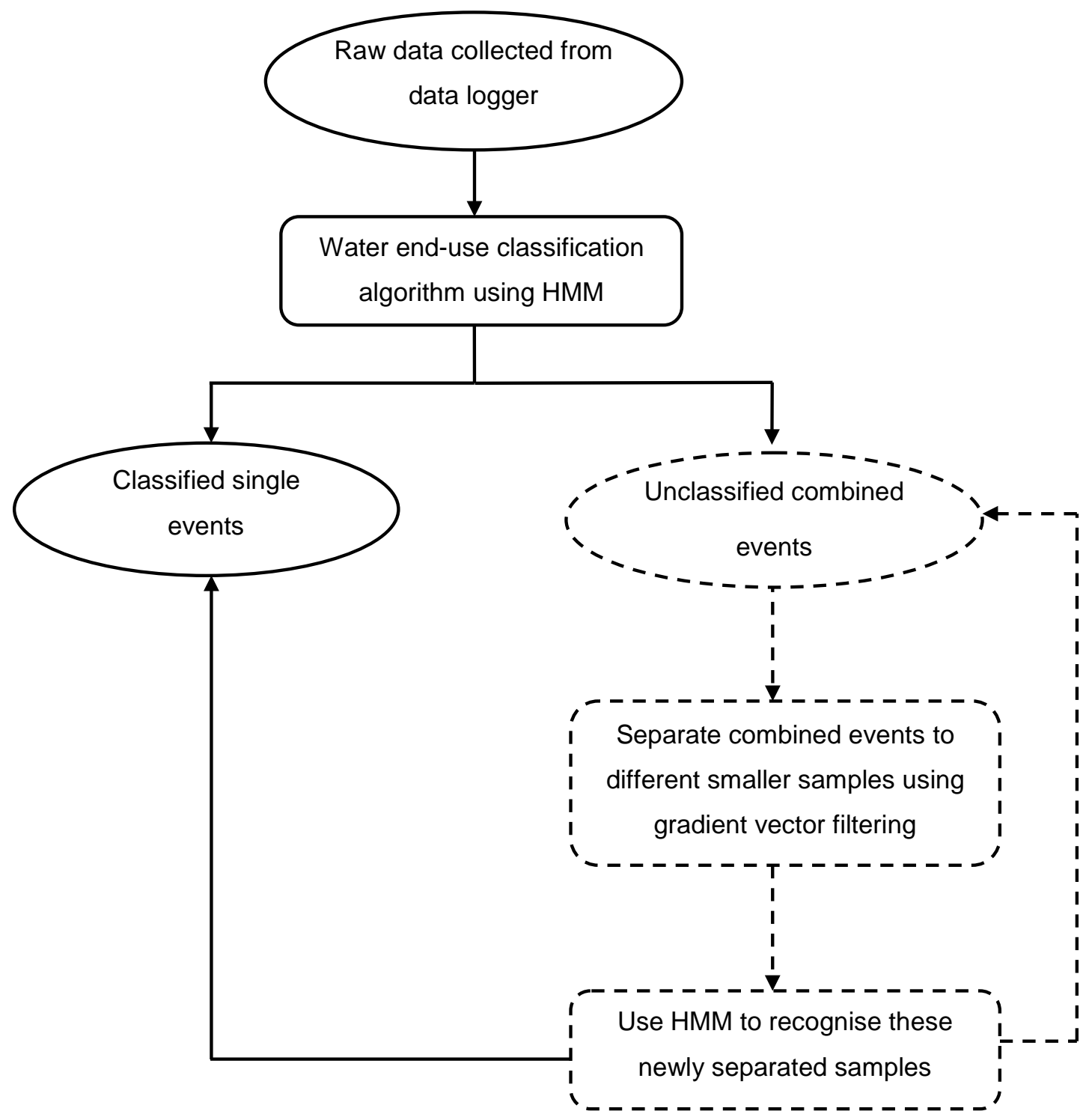


Figure 3 Single event analysis process (Nguyen et al., 2013a)

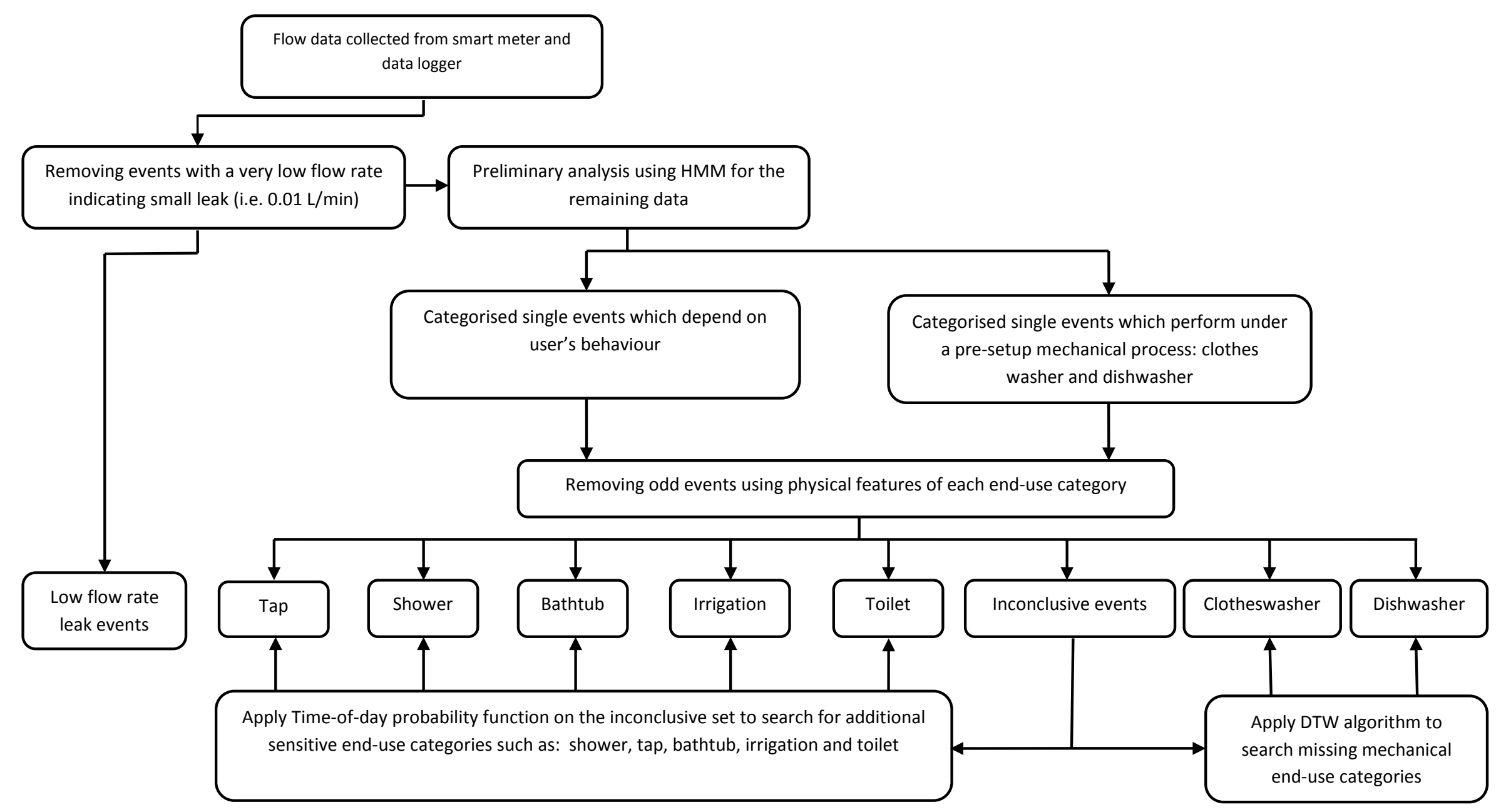


Figure 4 Combined event analysis process

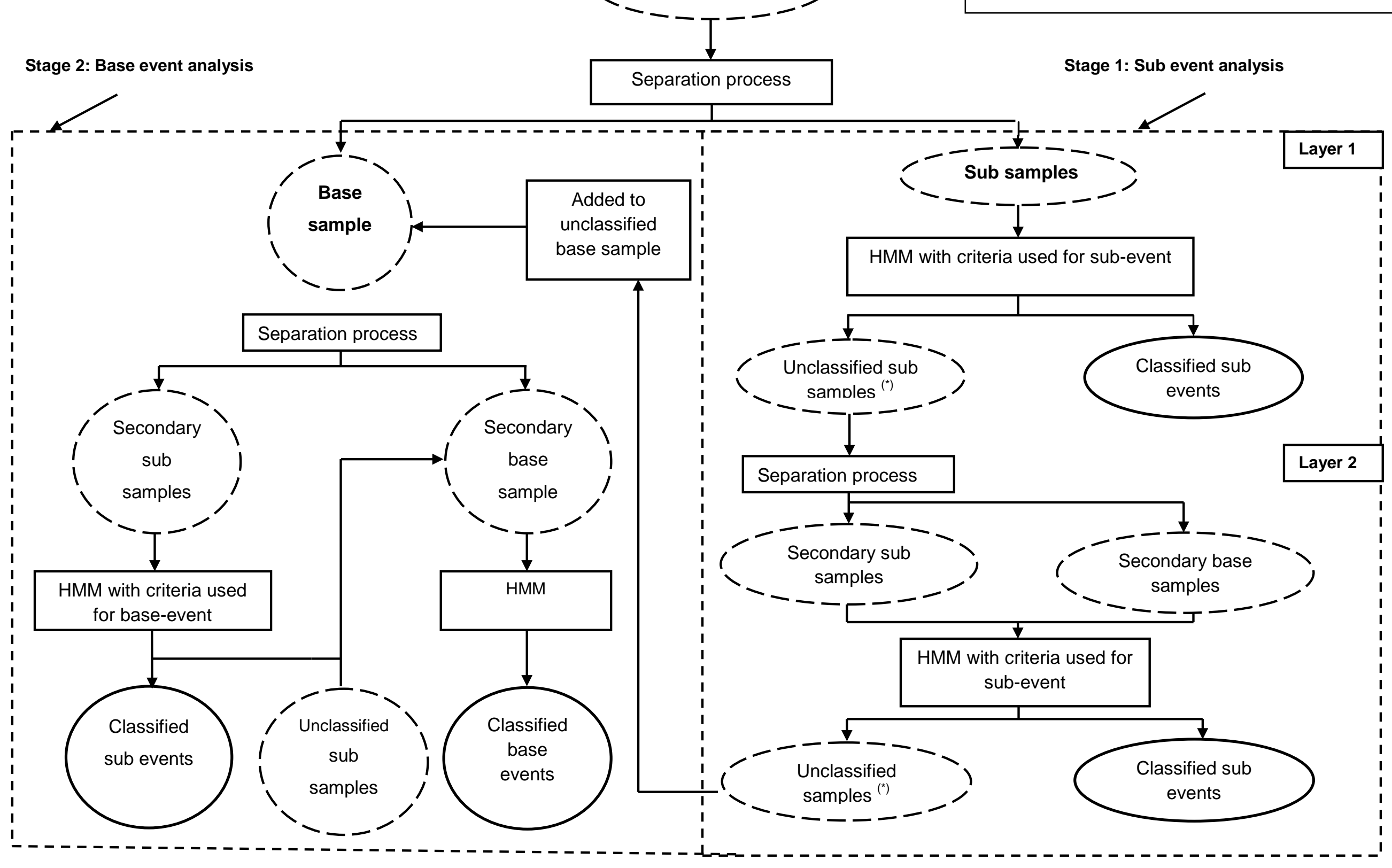

$(*)$ : any event whose likelihood is less than threshold value will remain unclassified. 
Figure 5 Possible overlapping positions of two random samples

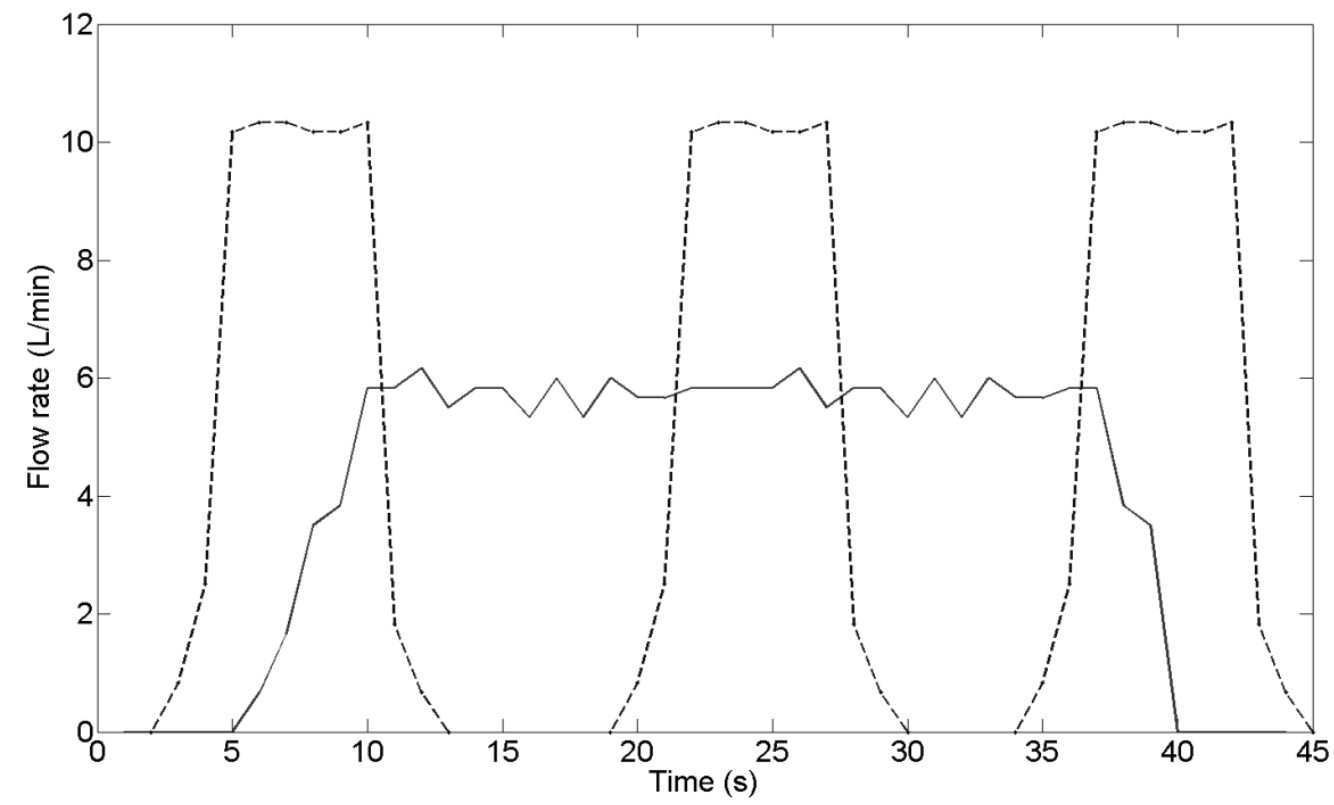


Figure 6a Original combined event for method illustration

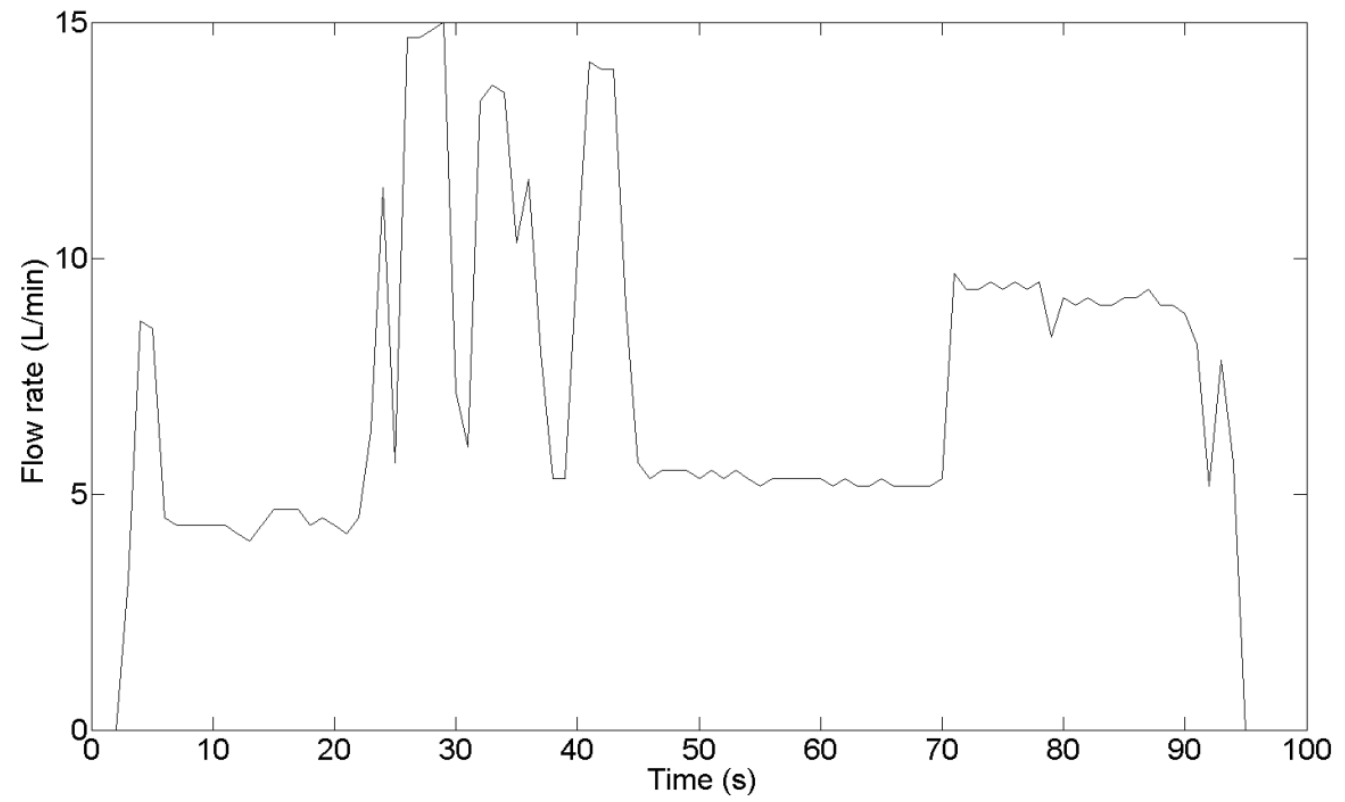


Figure 6b Gradient of the remaining combined sample

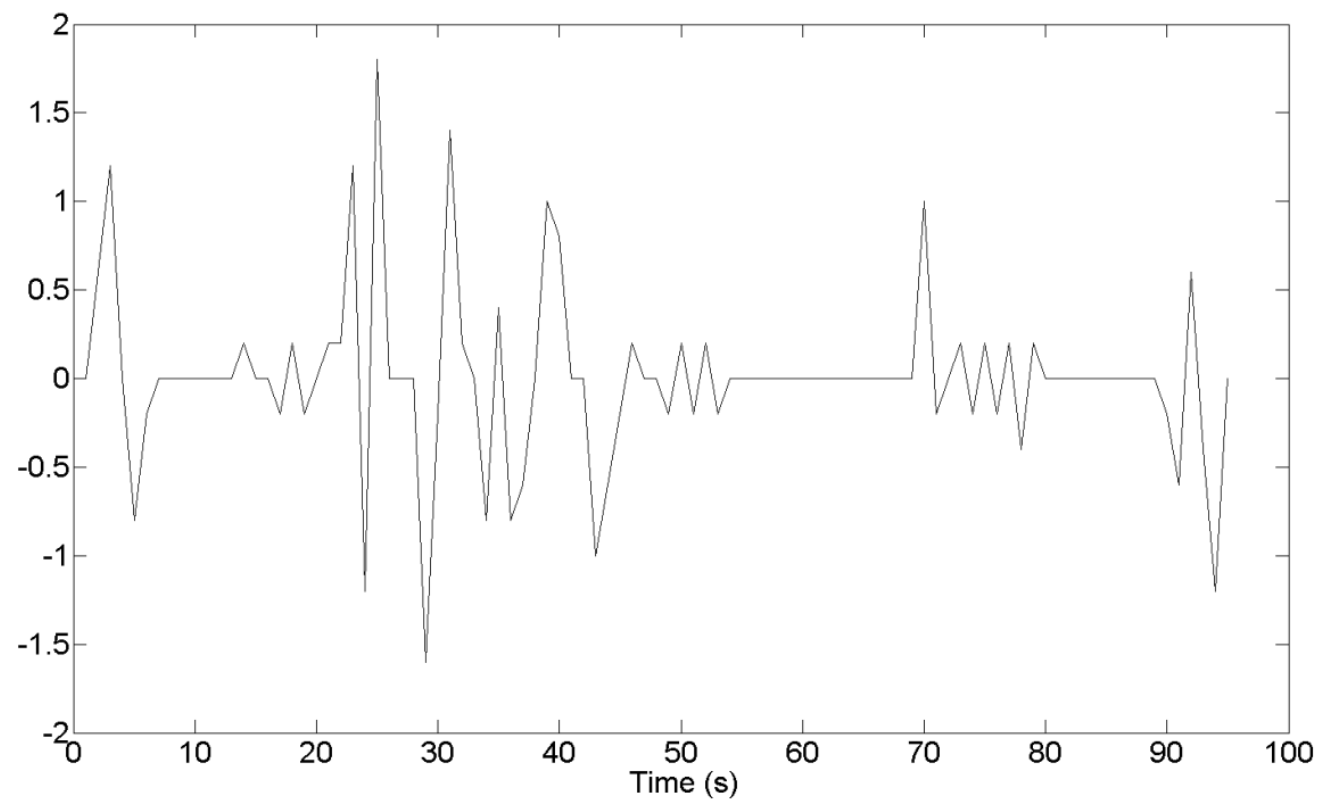


Figure 6c Filtered gradient vector

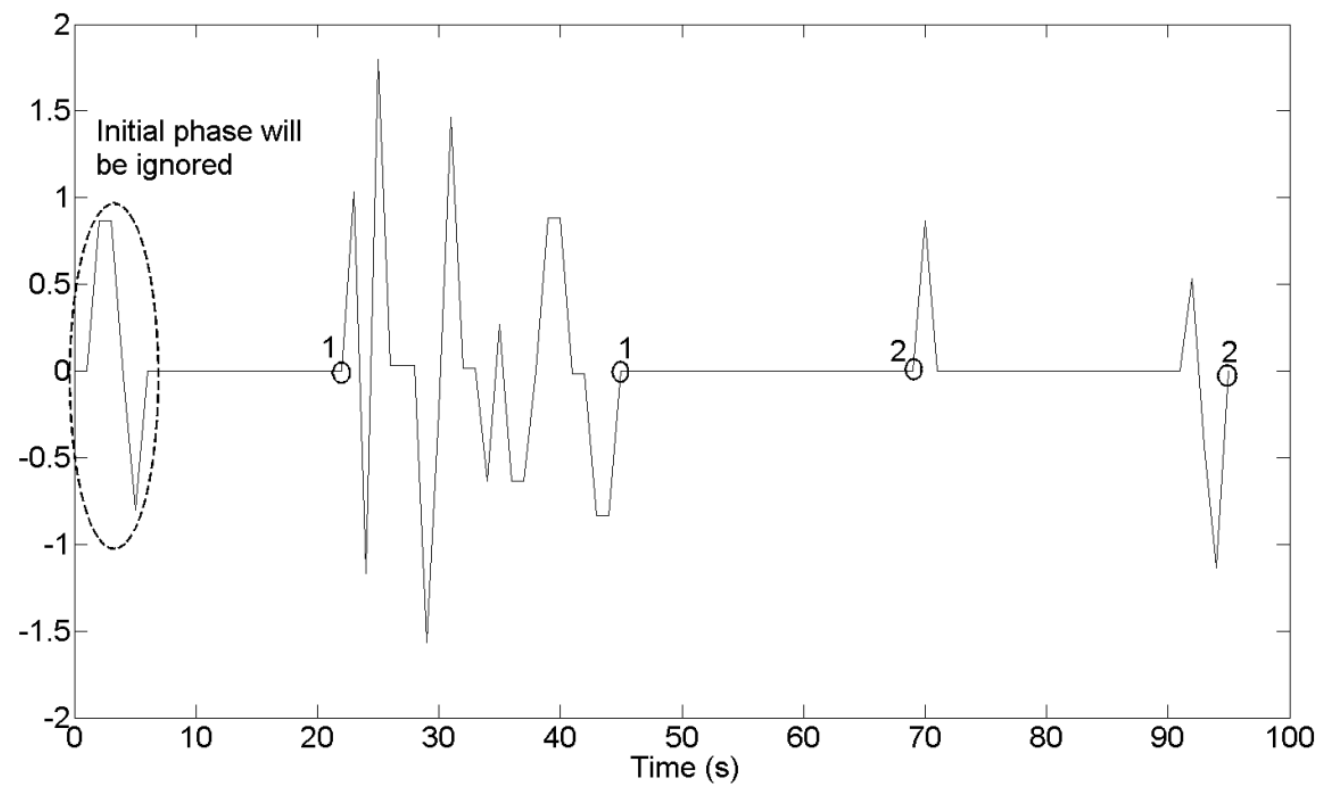


Figure 7 Achieved samples after separation process
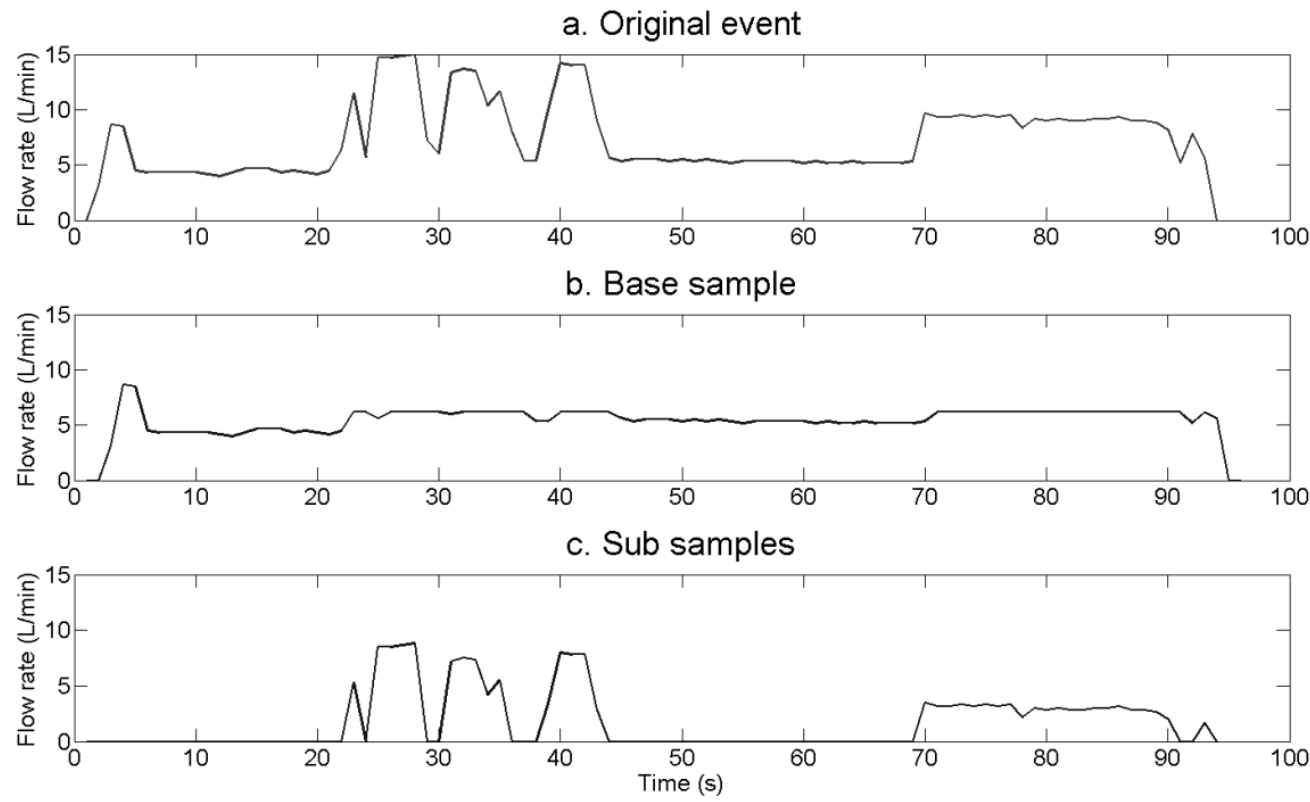
Figure 8 Actual singles events in the combined one

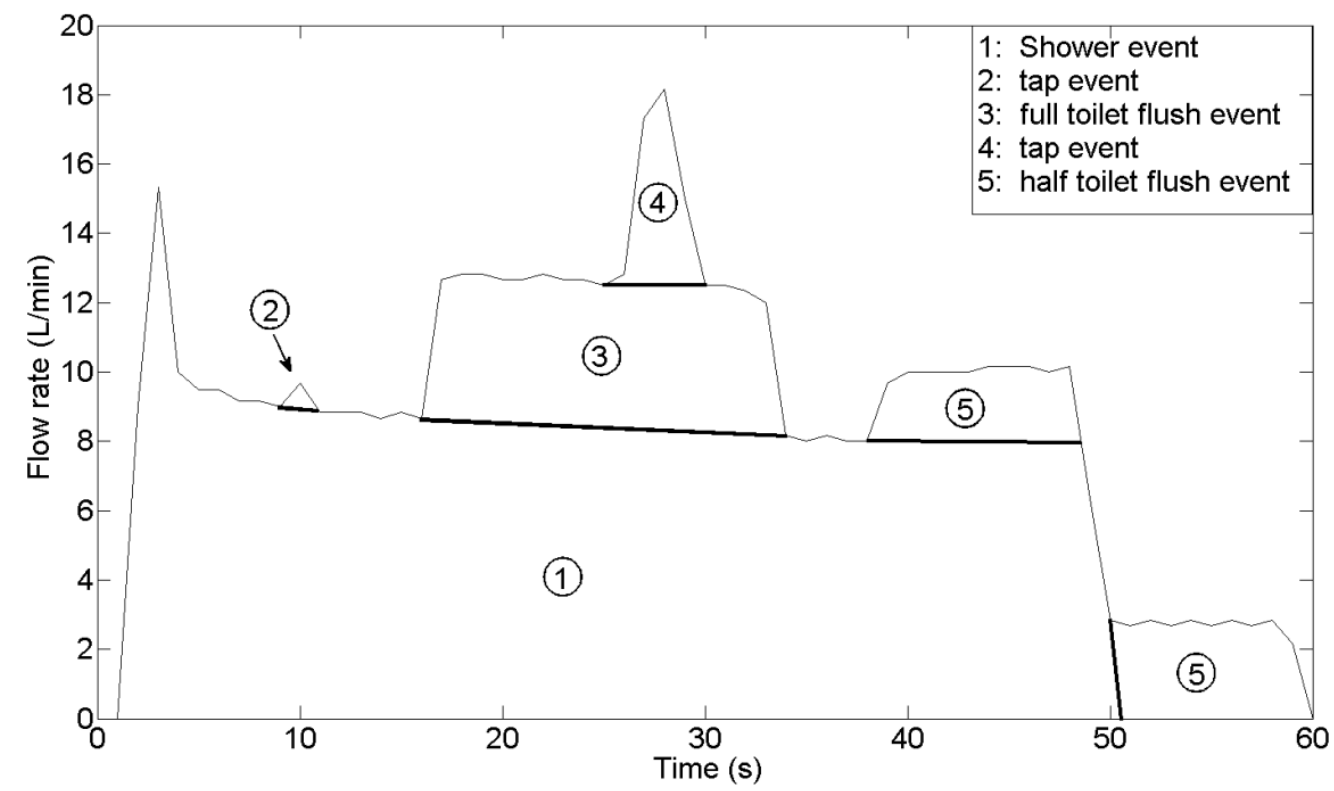


Figure 9 Separation of sub sample at starting and finishing phase

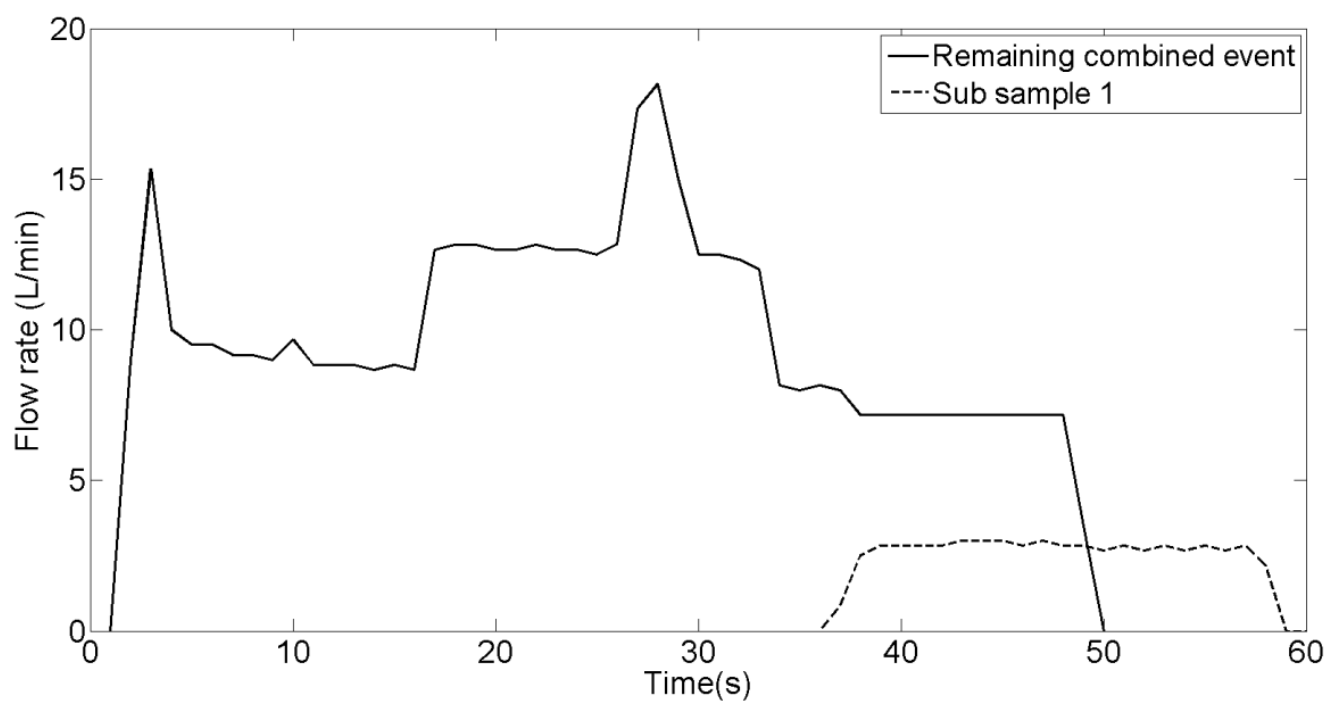


Figure 10 Gradient of the remaining sample

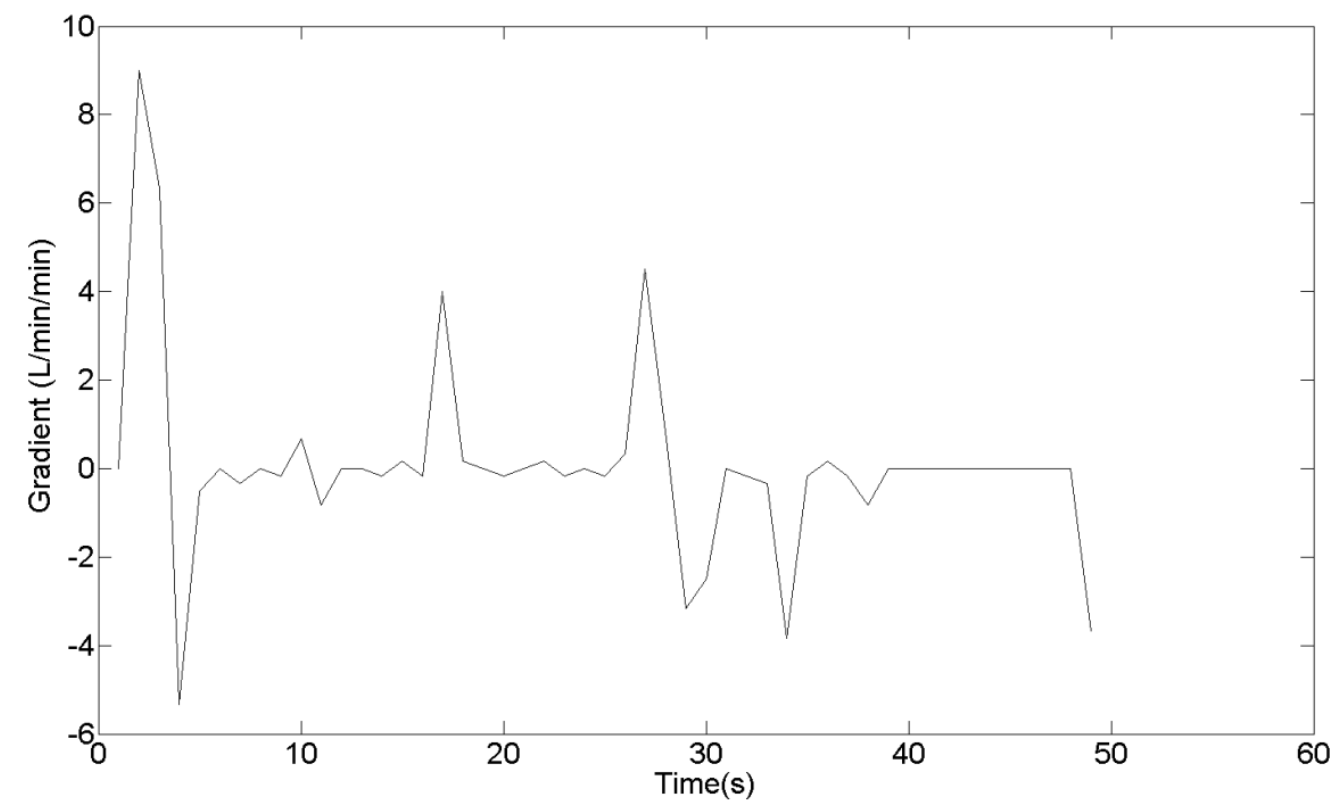


Figure 11 Filtered gradient of the remaining sample

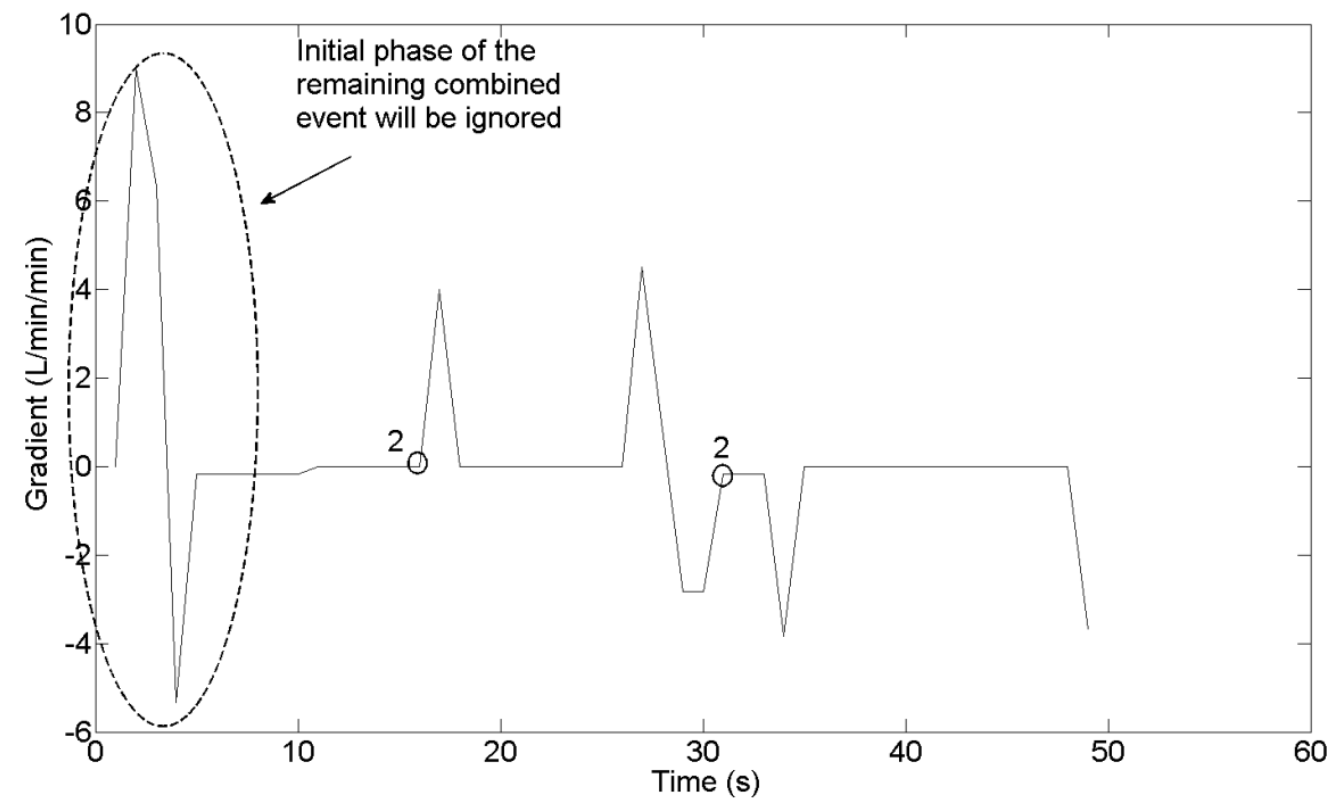


Figure 12 Products achieved from the separation process

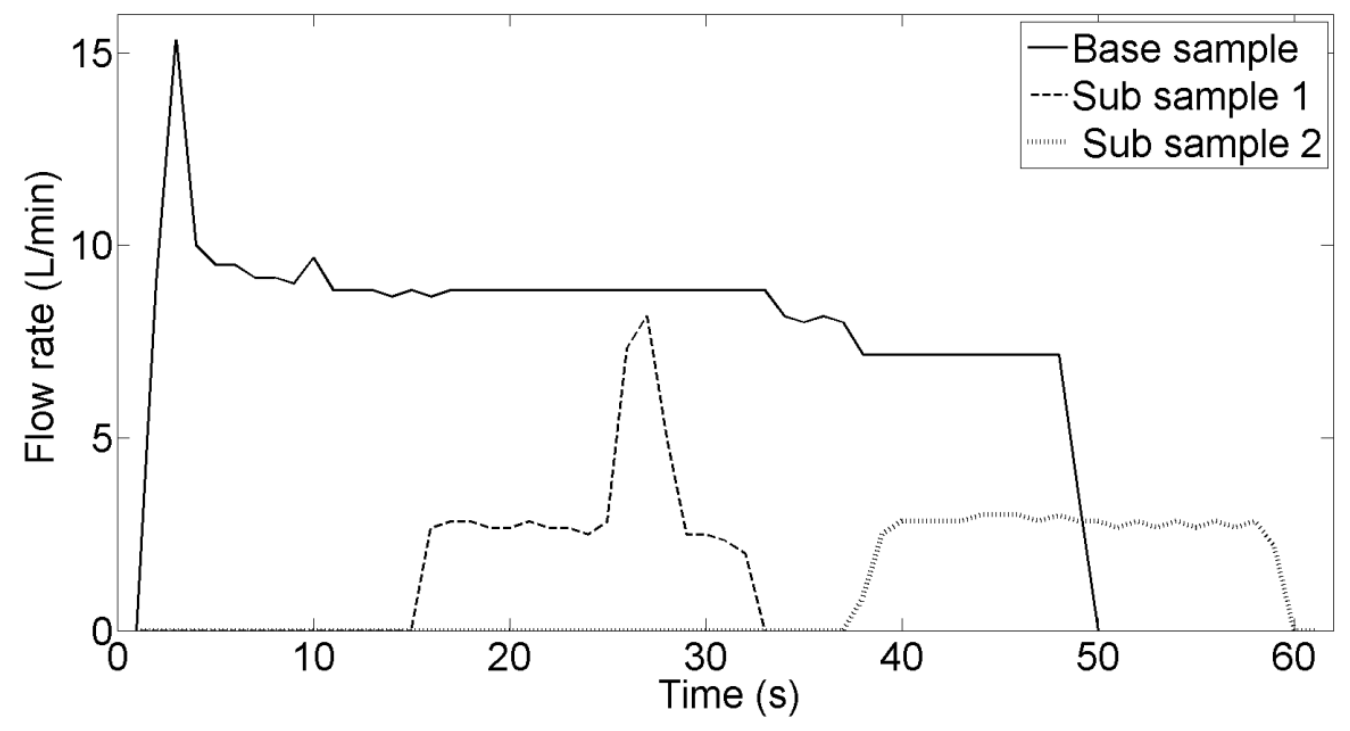


Figure 13 Sub samples achieved from the separation process

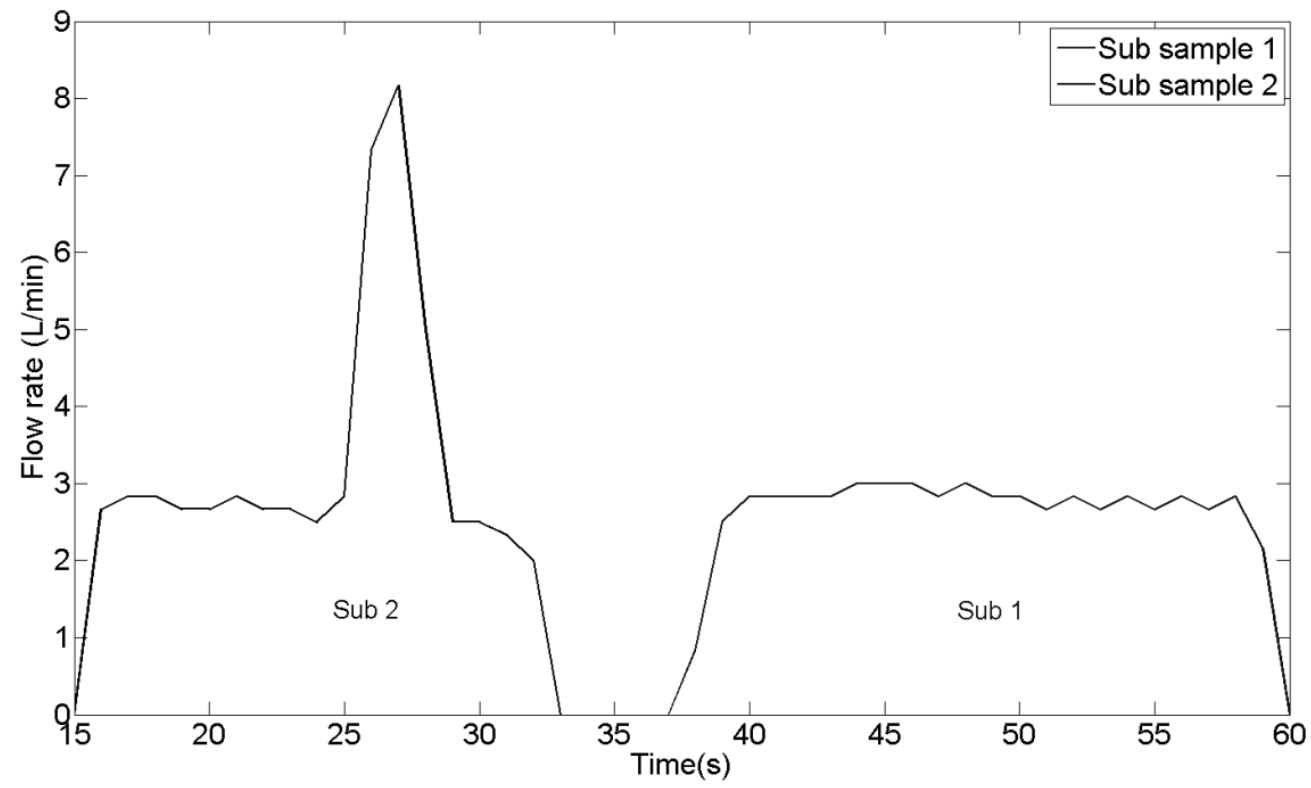


Figure 14 Two secondary sub samples achieved from the separation process

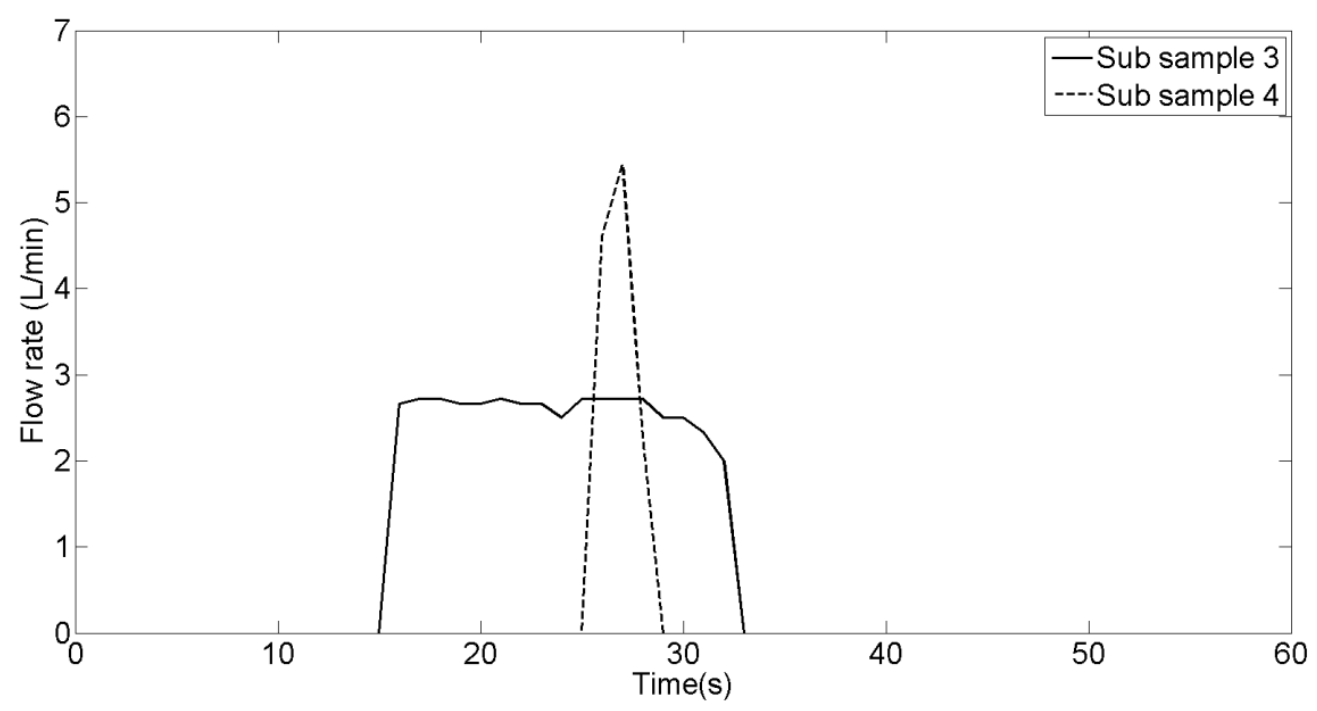


Figure 15 Base sample achieved from the separation process




Figure 16a

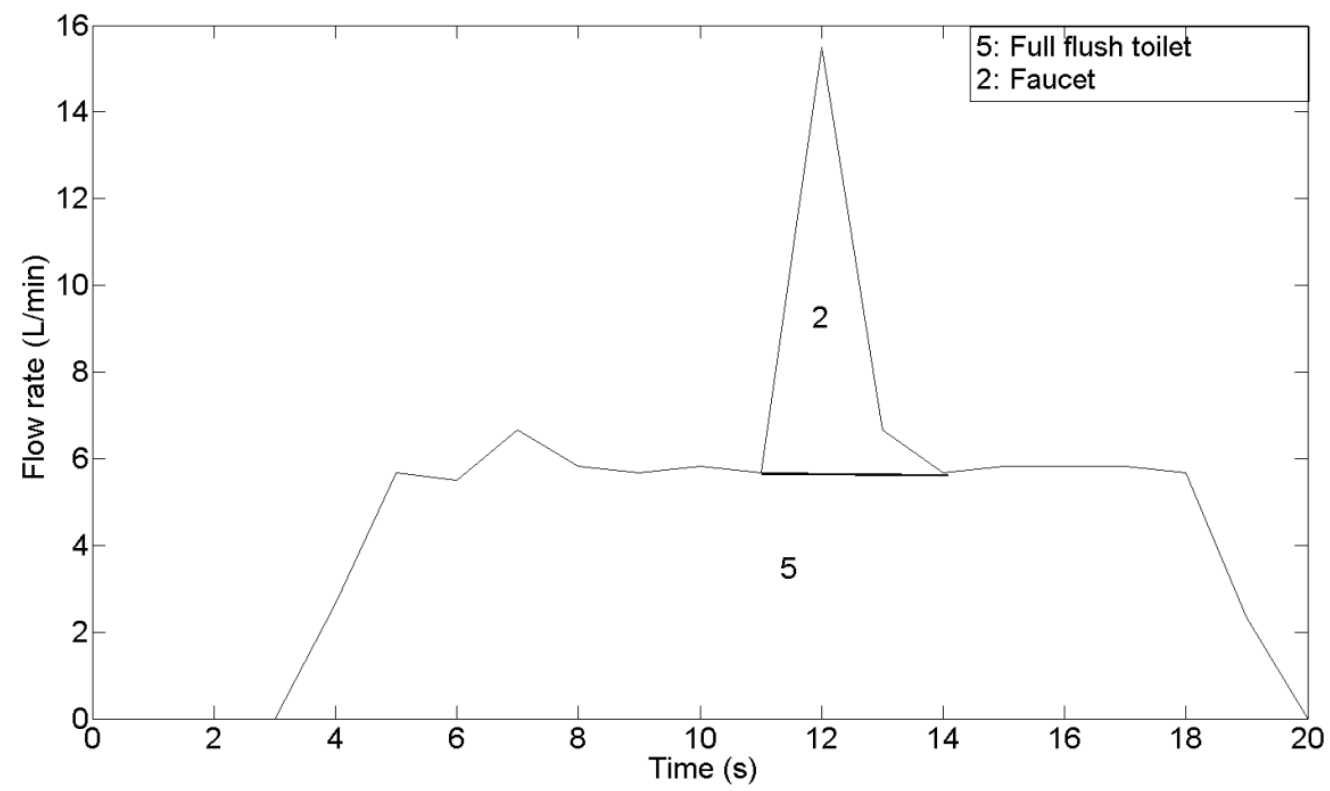


Figure 16b Type 2 independent combined event

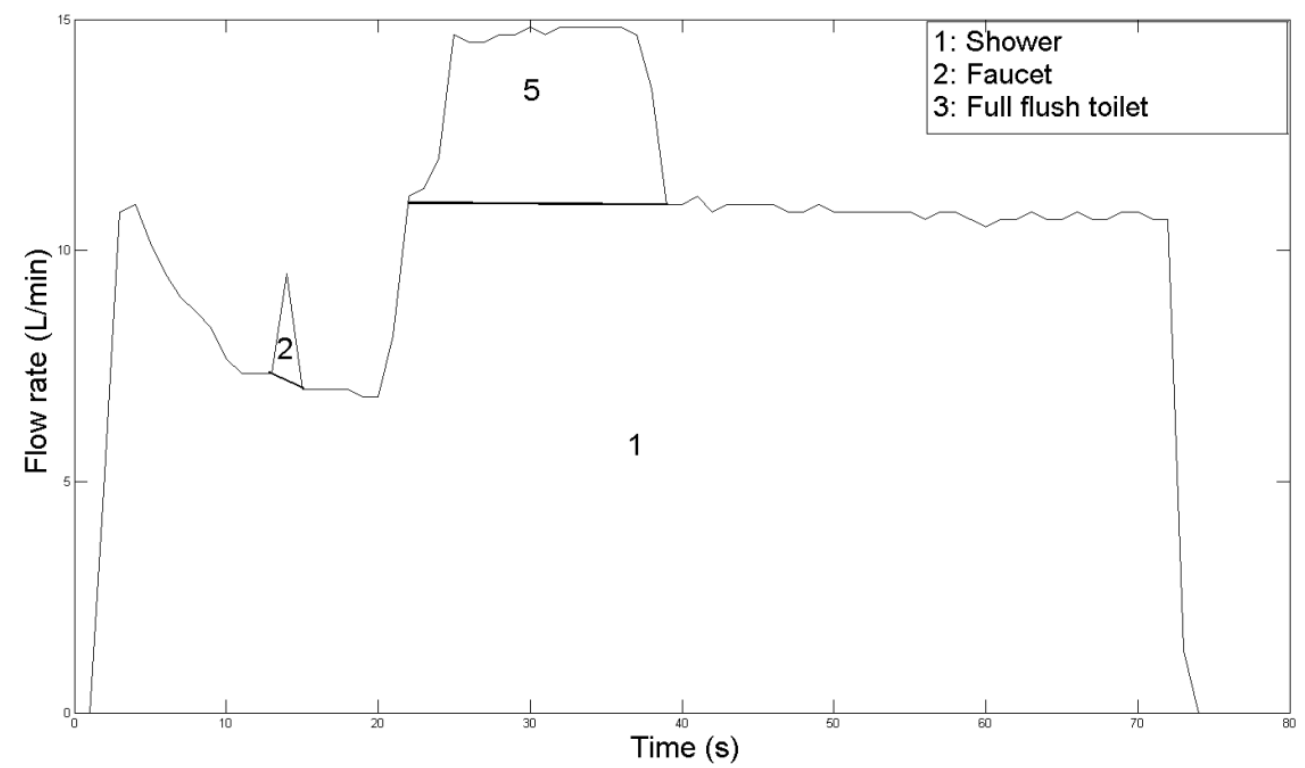


Figure 16c Type 3 independent combined event

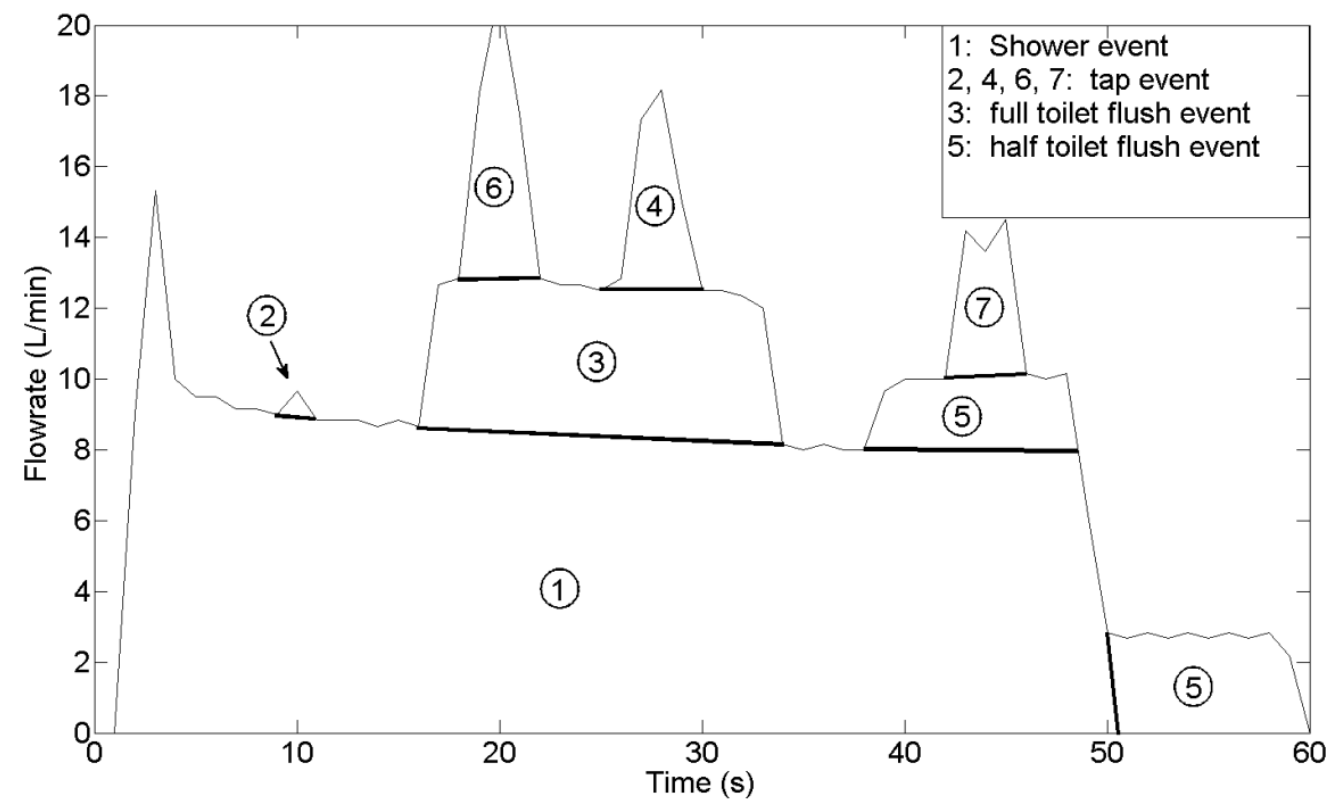


Table 1 Conducted water end use studies using smart water meter, data logger and pressure sensor (Beal and Stewart, 2012)

\begin{tabular}{|c|c|c|c|c|c|c|c|}
\hline Study & Location & $\begin{array}{l}\text { Sample } \\
\text { size (hh) }\end{array}$ & Sample regime & Dwelling type/s & Data capture & Data transfer and analysis & Reference \\
\hline $\begin{array}{l}2011 \text { - USA University of } \\
\text { Washington }\end{array}$ & Seattle, USA & 5 & 5 weeks & Mixture & Pressure sensor & $\begin{array}{l}\text { Data transferred wirelessly to } \\
\text { PC. Analysis using } \\
\text { HydroSense }\end{array}$ & $\begin{array}{l}\text { Froehlich et al. (2009; } \\
\text { 2011) }\end{array}$ \\
\hline $\begin{array}{l}2009 \text { - } 2011 \text { Gold Coast } \\
\text { Watersaver EUS }\end{array}$ & $\begin{array}{l}\text { Gold Coast, } \\
\text { Aust. }\end{array}$ & 252 & $\begin{array}{l}\text { Winter } 2008 \text { and } \\
\text { Summer } 2009\end{array}$ & $\begin{array}{l}\text { Single, } \\
\text { detached, dual } \\
\text { reticulation }\end{array}$ & $\begin{array}{l}\text { Actaris CT5-S meters, Aegis } \\
\text { Datacell R series loggers, } 10 \mathrm{sec} . \\
\text { int. }\end{array}$ & $\begin{array}{l}\text { Manual download to PC in- } \\
\text { situ Trace Wizard® }\end{array}$ & $\begin{array}{l}\text { Willis et al. (2010a, } \\
\text { 2011b) }\end{array}$ \\
\hline $\begin{array}{l}2008 \text {-USQ Investigation } \\
\text { of domestic water end use }\end{array}$ & $\begin{array}{l}\text { Toowoomba, } \\
\text { Aust. }\end{array}$ & 10 & $\begin{array}{l}\text { Continuous for } \\
138 \text { days }\end{array}$ & Single detached & $\begin{array}{l}\text { Actaris CT5-S meters, Monita R } \\
\text { series loggers, } 10 \text { sec. int. }\end{array}$ & $\begin{array}{l}\text { Wireless download - weekly } \\
\text { email Trace Wizard } ₫\end{array}$ & Mead (2008) \\
\hline $\begin{array}{l}2007 \text { - NZ Water End Use } \\
\text { and efficiency project }\end{array}$ & $\begin{array}{l}\text { Auckland } \\
\text { region }\end{array}$ & 51 & $\begin{array}{l}6 \text { months: across } \\
\text { summer and } \\
\text { winter }\end{array}$ & Single, detached & $\begin{array}{l}\text { Neptune disc meter, } 34.2 \text { pulses/L, } \\
\text { Branz data loggers, } 10 \text { sec int. }\end{array}$ & $\begin{array}{l}\text { Manual download to PC. } \\
\text { Trace Wizard } \AA\end{array}$ & Heinrich (2006) \\
\hline $\begin{array}{l}2005 \text { - Yarra Valley } \\
\text { Water Residential End } \\
\text { Use study }\end{array}$ & $\begin{array}{l}\text { Yarra Valley, } \\
\text { VIC, Aust. }\end{array}$ & 100 & $\begin{array}{l}2 \times 2 \text { wks summer } \\
\text { and winter }\end{array}$ & Single detached & $\begin{array}{l}\text { Actaris CT5 modified to } 72 \\
\text { pulses/L. Monatec XT logger, } 5 \text { sec } \\
\text { int. }\end{array}$ & $\begin{array}{l}\text { Manual download into MS } \\
\text { Access database. Trace } \\
\text { Wizard }{ }^{\circledR}\end{array}$ & Roberts (2005) \\
\hline $\begin{array}{l}2004 \text { - Tampa Water } \\
\text { Department Residential } \\
\text { Water Conservation Study }\end{array}$ & Florida, USA & 26 & $\begin{array}{l}2 \mathrm{wk} \text { baseline data } \\
+2 \times 2 \text { wk data } \\
\text { post retrofit }\end{array}$ & $\begin{array}{l}\text { High end users } \\
(230 \mathrm{~L} / \mathrm{p} / \mathrm{d})\end{array}$ & $\begin{array}{l}\text { Trident T-10 or Badger } 25 \text { meters, } \\
\text { Meter-Master loggers, }\end{array}$ & $\begin{array}{l}\text { Downloaded to PC and } \\
\text { Trace Wizard }{ }^{\circledR}\end{array}$ & Mayer et al. (2004) \\
\hline $\begin{array}{l}2003 \text { - Smart metering } \\
\text { project in UK }\end{array}$ & $\begin{array}{l}\text { Across } 10 \mathrm{UK} \\
\text { Water utilities }\end{array}$ & 250 & On going & Mixture & $\begin{array}{l}\text { Indentiflow }{ }^{\circledR} \text { smart meter }(0.01 \mathrm{~L} \\
\text { resolution) and data logger at } 1 \mathrm{~s} \text {. } \\
\text { intervals }\end{array}$ & $\begin{array}{l}\text { Analysis using Identiflow }{ }^{\circledR} \\
\text { software }\end{array}$ & $\begin{array}{l}\text { Kowalski and } \\
\text { Marshallsay (2005) }\end{array}$ \\
\hline $\begin{array}{l}\text { 1998-2001 WA Water } \\
\text { Corporation Domestic } \\
\text { Water Use study }\end{array}$ & $\begin{array}{l}\text { Perth, WA, } \\
\text { Aust. }\end{array}$ & $\begin{array}{l}120 \text { and } \\
600 \\
\text { surveys }\end{array}$ & $\begin{array}{l}18 \text { months for } \\
\text { single and } 13 \\
\text { months for multi }\end{array}$ & Single and multi & $\begin{array}{l}\text { Smart meters and loggers } \\
\text { (unspecified) }\end{array}$ & $\begin{array}{l}\text { Manual download to PC in- } \\
\text { situ and Trace Wizard }{ }^{\circledR}\end{array}$ & Loh and Coghlan (2003) \\
\hline $\begin{array}{l}1998 \text { USA and Canada } \\
\text { residential end use - } \\
\text { AWWA }\end{array}$ & USA/Canada & 1,188 & $\begin{array}{l}2 \times 2 \text { wks summer } \\
\text { and winter }\end{array}$ & Single detached & $\begin{array}{l}\text { Magnetic water meters, Meter } \\
\text { Master 100EL logger, } 10 \text { sec int. }\end{array}$ & $\begin{array}{l}\text { Manual logger and download } \\
\text { ex-situ and Trace Wizard® }\end{array}$ & Mayer et al. (2004) \\
\hline
\end{tabular}


Table 2 Existing pattern matching techniques and a rating of their applicability to the present study (Nguyen et al., 2013a)

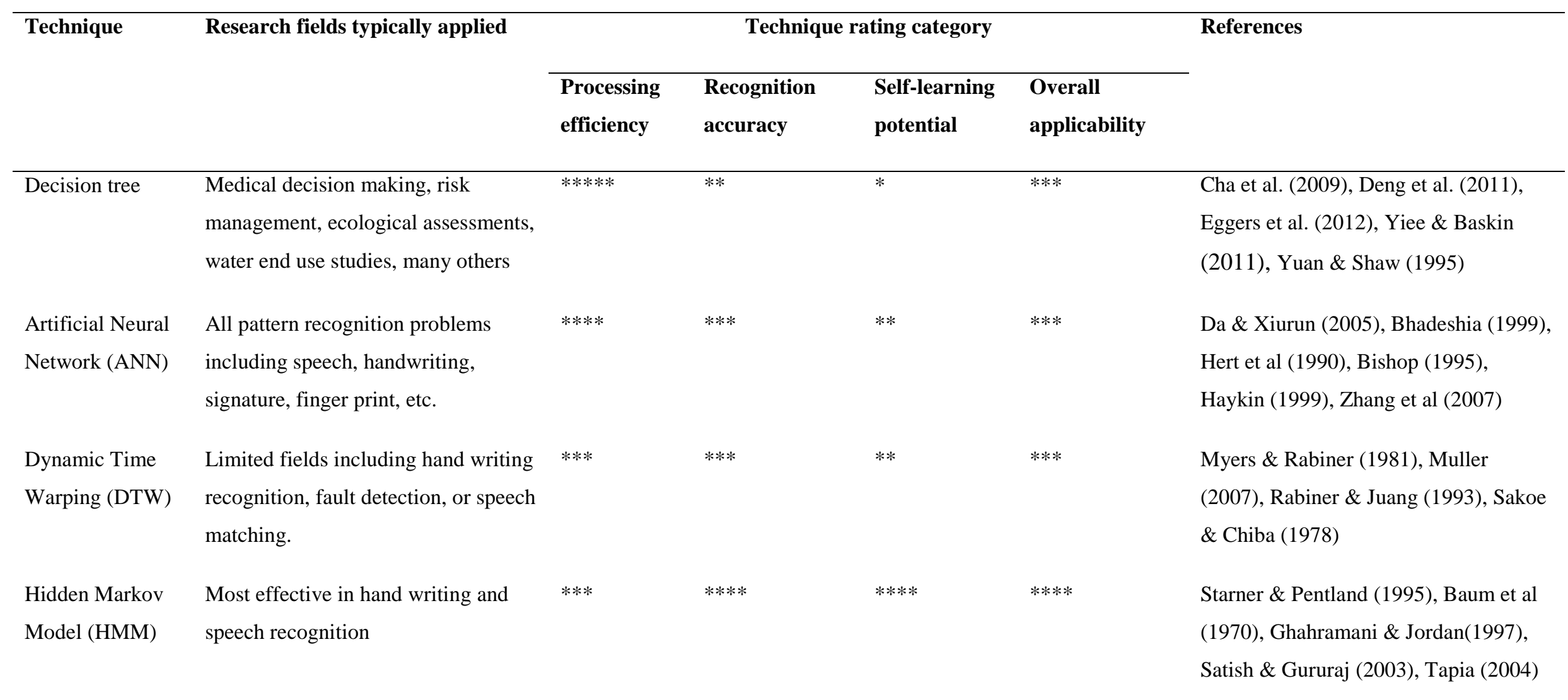


Table 3 Criteria for sample selection (Beal and Stewart, 2012)

\begin{tabular}{|c|c|}
\hline Criteria & Comment / Justification for criteria \\
\hline Consented to end use study & Ethical clearance requirement for all collaborating research partners. \\
\hline $\begin{array}{l}\text { Residential single detached } \\
\text { dwellings only }\end{array}$ & $\begin{array}{l}\text { Required to have a single residential water meter specific only to the } \\
\text { property being metered in order to capture single household data. }\end{array}$ \\
\hline $\begin{array}{l}\text { Only town (potable) water } \\
\text { supply to household }\end{array}$ & $\begin{array}{l}\text { Households which has more than one supply source internally plumbed } \\
\text { (e.g. rainwater tank or recycled water to toilet) was not included due to the } \\
\text { additional smart metering requirement. }\end{array}$ \\
\hline $\begin{array}{l}\text { Water meters accessible and } \\
\text { readily replaced with smart } \\
\text { meters and associated data }\end{array}$ & $\begin{array}{l}\text { Water meters need to be replaced with minimum disturbance to property. } \\
\text { Data transfer requires a clear GPRS network signal. Concrete lid may } \\
\text { reduce reception. In summary, the site was reviewed to ensure that it was }\end{array}$ \\
\hline loggers & fit-for-purpose for equipment installations and data collection reliability. \\
\hline Owner-occupied household & $\begin{array}{l}\text { Due to consent reasons and that water bills are payed for by the home } \\
\text { owner (i.e. landlord), only 'home owners' have been included in the study. } \\
\text { Also, rental households are typically transient and can move every 6-12 } \\
\text { months, thus not providing a good sample for seasonal comparisons. }\end{array}$ \\
\hline
\end{tabular}


Table 4 General characteristics of monitored households (Beal and Stewart, 2012)

\begin{tabular}{|c|c|c|c|c|c|c|c|c|c|c|c|c|}
\hline \multirow{2}{*}{$\begin{array}{l}\text { Household } \\
\text { Demograhics }\end{array}$} & \multicolumn{3}{|c|}{ Gold Coast } & \multicolumn{3}{|c|}{ Brisbane } & \multicolumn{3}{|c|}{ Ipswich } & \multicolumn{3}{|c|}{ Sunshine Coast } \\
\hline & $\begin{array}{l}\text { Winter } \\
2010\end{array}$ & $\begin{array}{l}\text { Summer } \\
2010-11\end{array}$ & $\begin{array}{l}\text { Winter } \\
2011\end{array}$ & $\begin{array}{l}\text { Winter } \\
2010\end{array}$ & $\begin{array}{l}\text { Summer } \\
2010-11\end{array}$ & $\begin{array}{l}\text { Winter } \\
2011\end{array}$ & $\begin{array}{l}\text { Winter } \\
2010\end{array}$ & $\begin{array}{l}\text { Summer } \\
2010-11\end{array}$ & $\begin{array}{l}\text { Winter } \\
2011\end{array}$ & $\begin{array}{l}\text { Winter } \\
2010\end{array}$ & $\begin{array}{l}\text { Summer } \\
2010-11\end{array}$ & $\begin{array}{l}\text { Winter } \\
2011 \\
\end{array}$ \\
\hline $\begin{array}{l}\text { No. of } \\
\text { households }\end{array}$ & 87 & 68 & 33 & 61 & 64 & 26 & 37 & 31 & 12 & 67 & 56 & 39 \\
\hline No. of people ${ }^{2}$ & 230 & 192 & 91 & 164 & 182 & 79 & 96 & 81 & 33 & 171 & 131 & 98 \\
\hline $\begin{array}{l}\text { Av. Household } \\
\text { occupancy }\end{array}$ & 2.6 & 3.0 & 3.2 & 2.6 & 2.8 & 3.0 & 2.7 & 2.6 & 2.8 & 2.5 & 2.4 & 2.6 \\
\hline $\begin{array}{l}\% \text { Households } \\
\text { with } \leq 2 \text { people }\end{array}$ & $58 \%$ & $46 \%$ & $42 \%$ & $41 \%$ & $47 \%$ & $42 \%$ & $51 \%$ & $58 \%$ & $50 \%$ & $46 \%$ & $64 \%$ & $59 \%$ \\
\hline $\begin{array}{l}\% \text { Households } \\
\text { pensioners/ } \\
\text { retired }\end{array}$ & $36 \%$ & $37 \%$ & $30 \%$ & $16 \%$ & $17 \%$ & $4 \%$ & $32 \%$ & $32 \%$ & $8 \%$ & $45 \%$ & $50 \%$ & $46 \%$ \\
\hline $\begin{array}{l}\text { Households } \\
\text { with children } \\
\text { (aged } \leq 17 \text { ) }\end{array}$ & $34 \%$ & $46 \%$ & $52 \%$ & $30 \%$ & $38 \%$ & $46 \%$ & $21 \%$ & $23 \%$ & $33 \%$ & $25 \%$ & $23 \%$ & $28 \%$ \\
\hline $\begin{array}{l}\text { Average age of } \\
\text { children (years) }\end{array}$ & 8.8 & 8.4 & 7.7 & 2.7 & 4.6 & 5.7 & 4.4 & 5.9 & 4.8 & 10 & 9.4 & 10.5 \\
\hline $\begin{array}{l}\text { Income bracket } \\
\text { split }^{3} \\
1: 2: 3: 4: 5: 6: 7\end{array}$ & $\begin{array}{c}\text { 13:11:8:6: } \\
\text { 4:0:2 }\end{array}$ & $\begin{array}{c}13: 15: 8: 11: 7 \\
: 4: 4\end{array}$ & $\begin{array}{c}\text { 5:8:5:3: } \\
\text { 3:3:3 }\end{array}$ & $\begin{array}{c}\text { 6:9:19:6: } \\
\text { 7:2:3 }\end{array}$ & $\begin{array}{c}\text { 5:9:18:6: } \\
\text { 9:3:3 }\end{array}$ & $\begin{array}{l}\text { 1:3:10: } \\
\text { 1:5:2:0 }\end{array}$ & $\begin{array}{c}\text { 8:6:8:5: } \\
3: 3: 1\end{array}$ & $\begin{array}{c}6: 6: 7: 3: 3 \\
: 3: 0\end{array}$ & $\begin{array}{c}1: 3: 2: 2: 3 \\
: 0: 0\end{array}$ & $\begin{array}{c}\text { 18:23:1 } \\
\text { 4:5:0:4: } \\
0\end{array}$ & $\begin{array}{c}14: 22: 9: 2 \\
: 0: 4: 0\end{array}$ & $\begin{array}{c}9: 14: 7: 1: \\
0: 3: 0\end{array}$ \\
\hline $\begin{array}{l}\text { Education level } \\
\text { split }^{4} \\
\text { PS:HS:T:U }\end{array}$ & 1:21: 9:19 & 1:24: 16:27 & $\begin{array}{l}0: 10: \\
9: 14\end{array}$ & $\begin{array}{l}0: 17: \\
10: 23\end{array}$ & $\begin{array}{c}1: 14: 10: 2 \\
4\end{array}$ & $\begin{array}{l}0: 5: \\
5: 15\end{array}$ & $\begin{array}{l}3: 12: \\
12: 9\end{array}$ & $\begin{array}{c}3: 12: \\
10: 6\end{array}$ & $2: 4: 4: 2$ & $\begin{array}{l}4: 14: \\
25: 26\end{array}$ & $\begin{array}{l}4: 10: \\
21: 21\end{array}$ & $\begin{array}{l}4: 7: \\
13: 15\end{array}$ \\
\hline
\end{tabular}

Notes: ${ }^{1}$ data presented are averages, ${ }^{2}$ this is based on known household occupancies at the time of the initial household water audit and also includes any updates to occupancies which were collated in March this year. This does not include any visitors or absent residents. ${ }^{3}$ income categories: $1=<\$ 30,000,2=\$ 30,000-\$ 59,000,3=\$ 60,000-\$ 89,999,4=\$ 90,000-\$ 119,999,5=\$ 120,000-\$ 149,999,6=\geq \$ 150,000,7=$ prefer not to respond. ${ }^{4}$ education categories are PS = primary school, $\mathrm{HS}=$ high school, $\mathrm{T}=$ trade/TAFE, $\mathrm{U}=$ university (includes post graduate). 
Table 5 Data allocation

\begin{tabular}{lc}
\hline End-use category & Collected samples \\
\hline Shower & 7,265 \\
Tap & 56,349 \\
Clothes washer & 8,975 \\
Dishwasher & 4,877 \\
Toilet & 15,468 \\
Bathtub & 496 \\
Irrigation & 1,290 \\
Combined events & 2,883 \\
\hline
\end{tabular}


Table 6 Required feature parameters for clothes washer, dishwasher and toilet event classification

\begin{tabular}{ll}
\hline End-use category & Feature parameters \\
\hline Clothes washer & Typical flow rate $-q_{t, 3}$ \\
Dishwasher & Typical flow rate $-q_{t, 4}$ \\
Toilet & Typical volume $-v_{t, 5,6}$ \\
& \\
\hline
\end{tabular}


Table 7 Number of samples classified to different end-use categories using HMM method

\begin{tabular}{lll}
\hline End-use category & $\begin{array}{l}\text { Number of classified } \\
\text { sample }\end{array}$ & $\begin{array}{l}\text { Corresponding } \\
\text { threshold value }\left(b_{i}\right)\end{array}$ \\
\hline Shower & 6175 & 0.0000267 \\
Faucet & 44076 & 0.0063820 \\
Clothes washer & 8257 & 0.0001280 \\
Dishwasher & 4389 & 0.0015148 \\
Full flush toilet & 7888 & 0.0001098 \\
Half Flush Toilet & 5507 & 0.0003098 \\
Irrigation & 1806 & 0.0000273 \\
Bathtub & 744 & 0.0000138 \\
\hline
\end{tabular}


Table 8 Final likelihood of one sample for sub event analysis

\begin{tabular}{lccccc}
\hline Category & $\begin{array}{c}\text { Original HMM } \\
\text { likelihood }\left(c_{i}\right)\end{array}$ & $\begin{array}{c}\text { Magnified } \\
\text { factor }\left(k_{m, i}\right)\end{array}$ & $\begin{array}{c}\text { Reduced } \\
\text { factor }\left(k_{r, i}\right)\end{array}$ & $\begin{array}{c}\text { Modified } \\
\text { likelihood } \\
\left(C_{i}\right)\end{array}$ & $\begin{array}{c}\text { Threshold value } \\
\text { checking }\left(b_{i}\right)\end{array}$ \\
\hline Faucet & $c_{2}$ & 1 & 1 & $C_{2}$ & $b_{2}$ \\
Clothes washer & $c_{3}$ & $k_{m, 3}$ & $k_{r, 3}$ & $C_{3}$ & $b_{3}$ \\
Dishwasher & $c_{4}$ & $k_{m, 4}$ & $k_{r, 4}$ & $C_{4}$ & $b_{4}$ \\
Full flush toilet & $c_{5}$ & 1 & $k_{r, 5}$ & $C_{5}$ & $b_{5}$ \\
Half flush toilet & $c_{6}$ & 1 & $k_{r, 6}$ & $C_{6}$ & $b_{6}$ \\
\hline
\end{tabular}


Table 9 Final likelihood of one sub sample in base event analysis

\begin{tabular}{lccccc}
\hline Category & $\begin{array}{c}\text { Original HMM } \\
\text { likelihood }\left(c_{i}\right)\end{array}$ & $\begin{array}{c}\text { Magnified } \\
\text { factor }\left(k_{m, i}\right)\end{array}$ & $\begin{array}{c}\text { Reduced } \\
\text { factor }\left(k_{r, i}\right)\end{array}$ & $\begin{array}{c}\text { Modified } \\
\text { likelihood }\left(C_{i}\right)\end{array}$ & $\begin{array}{c}\text { Threshold value } \\
\text { checking }\left(b_{i}\right)\end{array}$ \\
\hline Shower & $c_{1}$ & 1 & $k_{r, 1}$ & $C_{\mathbf{1}}$ & $b_{1}$ \\
Full flush toilet & $c_{5}$ & 1 & $k_{r, 5}$ & $C_{5}$ & $b_{5}$ \\
Bathtub & $c_{7}$ & 1 & $k_{r, 7}$ & $C_{7}$ & $b_{7}$ \\
Irrigation & $c_{8}$ & 1 & 1 & $C_{\mathbf{8}}$ & $b_{\mathbf{8}}$ \\
\hline
\end{tabular}


Table 10 Independent combined event description

\begin{tabular}{lcl}
\hline End-use category & Start time & Event description \\
\hline Shower & $8: 15: 00$ & 1 shower event in main bathroom \\
Basin tap & $8: 15: 30$ & 1 short tap event from basin \\
Main toilet & $8: 16: 00$ & 1 full toilet flush event \\
Kitchen tap & $8: 16: 35$ & 1 kitchen tap event \\
Ensuite toilet & $8: 17: 00$ & 1 half flush event \\
\hline
\end{tabular}


Table 11 Physical characteristics of all end-use devices in the surveyed home

\begin{tabular}{ll}
\hline End-use & Given information \\
\hline Clothes washer & 1 clothes washer cycle was found within \\
& 10 events prior to the combined one. \\
$\bullet$ & No clothes washer was found within the 10 \\
& events after the combined one. \\
$\bullet$ & Typical clothes washer flow rate of the \\
& surveyed home: 11.25 (L/min). \\
Dishwasher & No dishwasher event was found within the \\
& 10 events before and after the combined \\
& one. \\
Hull flush toilet & Typical dishwasher flow rate of the \\
& surveyed home: 2.33 (L/min). \\
& Typical volume of all half flush toilet \\
& events of the surveyed home: $3.11(\mathrm{~L})$. \\
\hline &
\end{tabular}


Table 12 Average disaggregation accuracy for all three types of combined event

\begin{tabular}{lcc}
\hline Type & $\mathrm{A}_{\mathrm{N}}$ & $\mathrm{A}_{\mathrm{V}}$ \\
\hline 1 & 100 & 98.9 \\
2 & 81.4 & 82.6 \\
3 & 82.7 & 82.4 \\
\hline Overall & & \\
\hline
\end{tabular}


Table 13 Disaggregation accuracy for each end-use category

\begin{tabular}{llll}
\hline Event category & $\begin{array}{l}\text { Number of events for } \\
\text { verification }\end{array}$ & $\begin{array}{l}\text { Number of correctly } \\
\text { disaggregated events }\end{array}$ & Accuracy (\%) \\
\hline Shower & 23 & 18 & 78.3 \\
Faucet & 163 & 142 & 87.1 \\
Clothes washer & 29 & 26 & 89.7 \\
Dishwasher & 24 & 20 & 83.3 \\
Toilet & 78 & 64 & 82.1 \\
Bathtub & 19 & 15 & 79.0 \\
Irrigation & 17 & 13 & 76.5 \\
\hline
\end{tabular}


Table 14 Comparison between the proposed technique with existing methods

\begin{tabular}{|c|c|c|c|c|}
\hline \multirow[t]{2}{*}{$\begin{array}{l}\text { Type of } \\
\text { combined event }\end{array}$} & \multicolumn{2}{|c|}{$\begin{array}{l}\text { Disaggregation accuracy using } \\
\text { Trace Wizard }\end{array}$} & \multicolumn{2}{|c|}{$\begin{array}{l}\text { Disaggregation accuracy using the } \\
\text { proposed method }\end{array}$} \\
\hline & $\mathrm{A}_{\mathrm{N}}$ & $A_{V}$ & $\mathrm{~A}_{\mathrm{N}}$ & $\mathrm{A}_{\mathrm{V}}$ \\
\hline $\begin{array}{l}\text { Type } 1-5 \\
\text { samples }\end{array}$ & 80 & 96.3 & 100 & 98.9 \\
\hline $\begin{array}{l}\text { Type } 2-35 \\
\text { samples }\end{array}$ & 64.3 & 65.2 & 81.4 & 82.6 \\
\hline $\begin{array}{l}\text { Type } 3-10 \\
\text { samples }\end{array}$ & 38.6 & 55.4 & 82.7 & 82.4 \\
\hline $\begin{array}{l}\text { Average } \\
\text { accuracy }\end{array}$ & 41.6 & 72.3 & 88.0 & 88.0 \\
\hline
\end{tabular}


A1. Sub1 event classification using HMM

\begin{tabular}{llll}
\hline End use & $\begin{array}{l}\text { Original HMM } \\
\text { Likelihood }\end{array}$ & Threshold value & Final output \\
\hline Faucet & $1.77 \times 10^{-6}$ & $6.38 \times 10^{-3}$ & The sample will \\
Clothes washer & $4.18 \times 10^{-13}$ & $1.28 \times 10^{-4}$ & be categorised \\
Dishwasher & $5.01 \times 10^{-4}$ & $1.51 \times 10^{-3}$ & as half flush \\
Full flush toilet & $2.61 \times 10^{-5}$ & $1.1 \times 10^{-4}$ & toilet \\
Half flush toilet & $\mathbf{3 . 2 6 \times \mathbf { 1 0 } ^ { - 3 }}$ & $\mathbf{3 . 1 \times \mathbf { 1 0 } ^ { - 4 }}$ & \\
\hline
\end{tabular}


A2. Sub2 event classification using HMM

\begin{tabular}{llll}
\hline End use & $\begin{array}{l}\text { Original HMM } \\
\text { Likelihood }\end{array}$ & Threshold value & Final output \\
\hline Faucet & $1.59 \times 10^{-10}$ & $6.38 \times 10^{-3}$ & Undetermined \\
Clothes washer & $1.17 \times 10^{-12}$ & $1.28 \times 10^{-4}$ & event \\
Dishwasher & $8.48 \times 10^{-11}$ & $1.51 \times 10^{-3}$ & $\rightarrow$ require \\
Full flush toilet & $3.67 \times 10^{-8}$ & $1.1 \times 10^{-4}$ & second layer \\
Half flush toilet & $\mathbf{1 . 5 5 \times \mathbf { 1 0 } ^ { - 6 }}$ & $\mathbf{3 . 1 \times 1 \mathbf { 1 0 } ^ { - 4 }}$ & analysis \\
\hline
\end{tabular}


A3. Sub3 event classification using HMM

\begin{tabular}{llll}
\hline End use & $\begin{array}{l}\text { Original HMM } \\
\text { Likelihood }\end{array}$ & Threshold value & Final output \\
\hline Faucet & $3.73 \times 10^{-5}$ & $6.38 \times 10^{-3}$ & $\begin{array}{l}\text { The sample will be } \\
\text { categorised as half } \\
\text { flush toilet }\end{array}$ \\
Clothes washer & $1.17 \times 10^{-6}$ & $1.28 \times 10^{-4}$ & \\
Dishwasher & $3.31 \times 10^{-5}$ & $1.51 \times 10^{-3}$ & \\
Full flush toilet & $4.48 \times 10^{-3}$ & $1.10 \times 10^{-4}$ & \\
Half flush toilet & $\mathbf{3 . 2 1 \times \mathbf { 1 0 } ^ { - 2 }}$ & $\mathbf{3 . 1 0 \times 1 0 ^ { - 4 }}$ & \\
\hline
\end{tabular}


A4. Sub4 event classification using HMM

\begin{tabular}{llll}
\hline End use & $\begin{array}{l}\text { Original HMM } \\
\text { Likelihood }\end{array}$ & Threshold value & Final output \\
& $\mathbf{3 . 1 1 \times 1 0 ^ { - 1 }}$ & $\mathbf{6 . 3 8 \times 1 0 ^ { - 3 }}$ & $\begin{array}{l}\text { The sample will } \\
\text { be categorised } \\
\text { Faucet }\end{array}$ \\
Clothes washer & $8.30 \times 10^{-3}$ & $1.28 \times 10^{-4}$ & faucet \\
Dishwasher & $1.90 \times 10^{-2}$ & $1.51 \times 10^{-3}$ & \\
Full flush toilet & $8.40 \times 10^{-3}$ & $1.10 \times 10^{-4}$ & \\
Half flush toilet & $1.68 \times 10^{-2}$ & $3.10 \times 10^{-4}$ & \\
\hline
\end{tabular}


A5. Base event classification using HMM

\begin{tabular}{lll}
\hline End use & Original HMM Likelihood & Final output \\
\hline Shower & $\mathbf{3 . 1 2} \times \mathbf{1 0}$ & $\begin{array}{l}\text { The sample will } \\
\text { be categorised as } \\
\text { Bathtub }\end{array}$ \\
Irrigation & $4.72 \times 10^{-13}$ & Shower \\
Full flush toilet & $2.78 \times 10^{-28}$ & \\
\hline
\end{tabular}


A6. Disaggregation accuracy for type 1 combined event

\begin{tabular}{llccc}
\hline Event number & \multicolumn{2}{c}{ Event description } & $\mathrm{A}_{\mathrm{N}}$ & $\mathrm{A}_{\mathrm{V}}$ \\
& & & \\
\cline { 2 - 4 } & Base event & Sub event & 100 & 100 \\
\hline 1 & 1 toilet & 1 tap & 100 & 100 \\
3 & 1 toilet & 1 tap & 100 & 94.6 \\
4 & 1 bathtub & 1 toilet & 100 & 100 \\
5 & 1 toilet & 1 tap & 100 & 100 \\
\hline
\end{tabular}


A7. Disaggregation accuracy for type 2 combined event

\begin{tabular}{|c|c|c|c|c|}
\hline \multirow{2}{*}{$\begin{array}{l}\text { Event } \\
\text { number }\end{array}$} & \multicolumn{2}{|r|}{ Event description } & \multirow[t]{2}{*}{$\mathrm{A}_{\mathrm{N}}$} & \multirow[t]{2}{*}{$A_{V}$} \\
\hline & Base event & Sub event & & \\
\hline 1 & 1 bathtub & 2 taps, 2 toilets & 80 & 99.5 \\
\hline 2 & 1 shower & 4 taps, 1 toilet & 83.3 & 97.8 \\
\hline 3 & 1 shower & 1 tap, 1 toilet & 66.7 & 99.3 \\
\hline 4 & 1 shower & 1 tap, 1 toilet & 66.7 & 90.4 \\
\hline 5 & 1 bathtub & 2 taps, 1 toilet & 100 & 100 \\
\hline 6 & 1 bathtub & 1 tap, 1 toilet & 66.7 & 97.1 \\
\hline 7 & 1 bathtub & 2 taps & 100 & 98.1 \\
\hline 8 & 1 shower & 1 tap, 1 toilet & 66.7 & 98.4 \\
\hline 9 & 1 shower & 7 taps & 87.5 & 81.9 \\
\hline 10 & 1 shower & 2 taps, 3 toilets & 83.3 & 90.5 \\
\hline 11 & 1 shower & 4 taps, 2 clothes washers & 85.7 & 95.6 \\
\hline 12 & 1 shower & 3 taps, 3 clothes washers, 1 toilet & 75 & 97.9 \\
\hline 13 & 1 irrigation & 6 taps, 1 toilet, 2 dishwashers & 70 & 4.6 \\
\hline 14 & 1 bathtub & 5 taps, 2 toilets, 1 clothes washer & 77.8 & 96.7 \\
\hline 15 & 1 bathtub & $\begin{array}{l}2 \text { taps, } 1 \text { toilet, } 3 \text { clothes washers, } 2 \\
\text { dishwashers }\end{array}$ & 77.8 & 94.0 \\
\hline 16 & 1 bathtub & 4 taps, 2 toilets & 428 & 106 \\
\hline 17 & 1 shower & 6 taps, 2clothes washers & 77.8 & 276 \\
\hline 18 & 1bathtub & 2 taps, 2 toilets, 1 clothes washer & 83.3 & 92.5 \\
\hline 19 & 1 shower & 5 taps, 2 clothes washers, 1 toilet & 81.8 & 94.4 \\
\hline 20 & 1 shower & 1 tap, 2 toilets, 2 dishwashers & 50 & 40.9 \\
\hline 21 & 1 shower & 2 taps, 2 toilets, 2 dishwashers & 57.1 & 97.9 \\
\hline 22 & 1 shower & 2 taps, 1 toilet, 2 clothes washers & 83.3 & 96.6 \\
\hline 23 & 1 irrigation & 2 taps, 1 toilet, 2 clothes washers & 66.7 & 9.6 \\
\hline 24 & 1 irrigation & 2 taps, 1 toilet, 2 dishwashers & 83.3 & 94.1 \\
\hline 25 & 1 bathtub & $\begin{array}{l}1 \text { tap, } 2 \text { clothes washers, } 2 \\
\text { dishwashers }\end{array}$ & 100 & 100 \\
\hline
\end{tabular}


2 taps, 2 toilets

\begin{tabular}{|c|c|c|c|c|}
\hline 26 & 1 bathtub & 3 taps, 1 toilet & 66.7 & 71.9 \\
\hline 27 & 1 bathtub & 2 taps, 1 toilet, 1 dishwasher & 100 & 100 \\
\hline 28 & 1 shower & 1 tap, 2 clothes washers, 1 toilet & 100 & 100 \\
\hline 29 & 1 irrigation & 6 taps, 1 dishwasher & 100 & 100 \\
\hline 30 & 1 shower & 1 tap, 2 toilets, 2 dishwashers & 100 & 100 \\
\hline 31 & 1 shower & $\begin{array}{l}2 \text { taps, } 1 \text { toilet, } 1 \text { clothes washer, } \\
\text { dishwasher }\end{array}$ & 83.3 & 27.4 \\
\hline 32 & 1 irrigation & $\begin{array}{l}2 \text { taps, } 1 \text { toilet, } 1 \text { clothes washer, } \\
\text { dishwasher }\end{array}$ & 100 & 100 \\
\hline 33 & 1 irrigation & $\begin{array}{l}5 \text { taps, } 1 \text { toilet, } 1 \text { clothes washer } \\
6 \text { taps, } 4 \text { toilet }\end{array}$ & 83.3 & 95.1 \\
\hline 34 & 1 shower & & 87.5 & 92.1 \\
\hline 35 & 1 shower & & 100 & 100 \\
\hline
\end{tabular}


A8. Disaggregation accuracy for type 3 combined event

\begin{tabular}{|c|c|c|c|c|}
\hline \multirow{2}{*}{$\begin{array}{l}\text { Event } \\
\text { number }\end{array}$} & \multicolumn{2}{|r|}{ Event description } & \multirow[t]{2}{*}{$\mathrm{A}_{\mathrm{N}}$} & \multirow[t]{2}{*}{$A_{V}$} \\
\hline & Base event & Sub event & & \\
\hline 1 & 1 shower & 2 taps, 2 toilets & 80 & 99.8 \\
\hline 2 & 1 shower & 2 taps, 1 toilet & 100 & 99.3 \\
\hline 3 & 1 bathtub & 3 taps, 1 toilet & 80 & 94.6 \\
\hline 4 & 1 bathtub & 3 taps, 2 toilets & 83.3 & 94.5 \\
\hline 5 & 1 irrigation & $\begin{array}{l}14 \text { taps, } 1 \text { bathtub, } 1 \text { shower, } 2 \\
\text { toilet, } 3 \text { clothes }\end{array}$ & 90.5 & 44.8 \\
\hline 6 & 1 shower & 1 tap, 2 toilets, 1 bathtub & 80 & 81.1 \\
\hline 7 & 1 irrigation & 4 taps, 2 toilets, 1 bathtub & 87.5 & 63.4 \\
\hline 8 & 1irrigation & 1 shower, 1 bathtub & 66.7 & 70.6 \\
\hline 9 & 1 shower & 7 taps & 87.5 & 81.9 \\
\hline 10 & 1 irrigation & 3 taps, 3 toilets & 77.4 & 94.5 \\
\hline
\end{tabular}

